\title{
Phonetic variation and change in the Cockney Diaspora: the role of place, gender and identity
}

\begin{tabular}{|c|l|}
\hline Journal: & Language in Society \\
\hline Manuscript ID & LSY-A-19-133.R3 \\
\hline Keywords: & $\begin{array}{l}\text { Cockney, Phonetic variation and change, indexicality, dialect levelling, } \\
\text { gender, identity }\end{array}$ \\
\hline Abstract: & $\begin{array}{l}\text { Recent research has suggested that two linguistic processes are } \\
\text { displacing Cockney: the emergence of Multicultural London English (MLE) } \\
\text { in inner London and dialect levelling (e.g., Kerswill \& Williams, 2005). } \\
\text { This study investigates firstly, whether Cockney phonetic features have } \\
\text { 'moved East' to Essex (Fox, 2015), and secondly, the features' } \\
\text { indexicality in relation to place and identity. Fifty-four participants from } \\
\text { Debden, an outpost of the Cockney Diaspora, completed a sociolinguistic } \\
\text { inderview. Vowel measurements were made from a wordlist and passage, } \\
\text { and quantitative attitudinal and qualitative data were extracted from a } \\
\text { questionnaire and interviews. Overall, changes in identity as a result of } \\
\text { social change exceeded linguistic changes, and linguistic labels were not } \\
\text { interpreted uniformly across the community. Whilst Cockney variants } \\
\text { were largely maintained in young speakers, they were transposed onto } \\
\text { an 'Essex' accent. Furthermore, some young women but no young men } \\
\text { considered themselves Cockney, likely due to the matrifocal nature of } \\
\text { Cockney. }\end{array}$ \\
\hline
\end{tabular}

\section{SCHOLARONE \\ Manuscripts}




\section{Introduction}

Much recent work on London English has suggested that two separate linguistic processes have displaced or are in the process of displacing the Cockney vernacular; (1) dialect levelling across Southeast England and the London peripheries (Williams \& Kerswill 1999; Kerswill \& Williams 2005; Torgersen \& Kerswill 2004) and (2) the emergence of Multicultural London English (MLE) in the traditional East End of London which has partially diffused to outer London (Cheshire, Kerswill, Fox \& Torgersen 2011; Kerswill, Torgersen \& Fox 2008; Fox 2015). MLE is characterized by contact between the diverse multidialectal and multilingual communities that now make up the majority of the population in the traditional East End of London (cf., Vertovec 2007), and it has been argued that as a result, what we think of as traditional Cockney will be lost within the next 20 years (Cheshire et al. 2011; Fox 2015). However, if linguistic features are not just markers of belonging to a particular place, but also reflect social identity and community affiliation (e.g., Eckert 2008; Moore 2010), it is possible that Cockney may continue to be used in some communities. For example, it has been suggested that Cockney has moved east to Essex (Fox 2015), along with the traditional East End communities who relocated in the 'Cockney Diaspora' (Watt, Millington \& Huq 2014). However, if we understand that place is symbolic and culturally defined (Johnstone, Andrus \& Danielson 2006; Montgomery \& Moore 2017) there may be a disconnect between the phonetic features found in the community and the way they are labelled and categorised. This could mean that communities of East Londoners who now reside in Essex do not identify as Cockney. That is, the Cockney identity may not have moved east with the community. Further, even if Cockney phonetic features are maintained, young people may not label this variety as 'Cockney' as this term is strongly associated with East London (cf. 
Johnstone et al. 2006; Montgomery \& Moore 2017). In this paper, we assess firstly, the extent to which Cockney phonetic features have 'moved east' (Fox 2015) to the Debden Estate in Essex. Secondly, we investigate the way in which linguistic features are used to index place and identity in relation to Debden's specific cultural, social and historical background.

\subsection{Community of interest: The Cockney Diaspora and the Debden Estate}

As well as being the name of a language variety, 'Cockney' is also the name given to a group of people. Traditionally, a Cockney is considered to be an individual who was born within the sound of the Bow Bells in Cheapside, the City of London, and lived in London's traditional East End. However, over the last century, the 'Cockney Diaspora' has seen traditional East London communities relocate to the London peripheries, the home counties and in particular, to Essex (see Fox 2015; Watt, et al. 2014). No single reason led to the mass relocation of traditional, white, working-class East Londoners into Essex. Instead, the 'Cockney Diaspora' emerged as a result of a wide range of inter-related factors such as the deindustrialisation of the East End and the slum clearance programmes which ran between the 1920s and the 1960s (Watt et al. 2014).

The Greater London Plan was part of a series of successive governmental slum clearance programmes which sought to reduce East London's poverty and overcrowding by constructing purpose-built towns and housing estates outside of London (Abercrombie 1944). As part of the Greater London Plan, in 1949, the construction of the Debden Estate (or Debden) began in the town of Loughton, Essex. By 1953, Debden comprised 4,321 homes (Powell 1956) with an estimated population of 15,000 people, almost all of whom were white, working-class East Londoners (Carter 2006). Debden has remained largely 
separate from the surrounding area and has separate schools, high streets, stations, markets and churches from Loughton. Loughton, where Debden is situated, is in the county of Essex, approximately 5 miles from the London border (see Fig. 1).

The town is well connected to central London and is directly connected via the London Underground to London Liverpool Street station in the City of London. Since Debden was constructed, the official geographic delimiters of East London and the neighbouring county of Essex have been re-shaped. Traditionally the term 'East End' covered modern-day Tower Hamlets and southern parts of Hackney (Fox 2015). Nonetheless, the London Government Act 1963 saw the areas that now constitute the boroughs of Waltham Forest, Redbridge, Havering, and Barking and Dagenham transferred from Essex to Greater London. Therefore, there has been an expansion of what could be considered 'East London' or the 'East End'. As shown in Fig. 1, although Loughton is officially outside of the jurisdiction of Greater London and is situated in the county of Essex, it borders East London. Debden is geographically as close (if not closer) to the City of London as several outer-London boroughs, e.g., Havering, where some MLE features have been found in young speakers (Cheshire, Fox, Kerswill \& Torgersen 2008; Cheshire et al. 2011; Kerswill, Torgersen et al. 2008; Kerswill, Cheshire, Fox \& Torgersen 2008).

----- Figure 1 about here -----

\subsection{The linguistic context: language variation and change in the vowel system in Southeast England and London}

On a linguistic level, the Cockney vernacular has been described as both innovative and highly stigmatised (e.g., Wells 1982); Wells considered it to be 'overtly despised, but covertly imitated' (Wells, 1994:205). Although Cockney has been traditionally associated with East 
London (Wells 1982; Sivertsen 1960), in modern times, Cockney variants are not typically found among young speakers in East London (Cheshire et al. 2011; Kerswill, Cheshire et al. 2008; Fox 2015). Over the past century, the traditional East End, the area with which Cockney is primarily associated, has undergone a vast transformation. Though the East End has always been a centre for immigration, modern-day East London has become increasingly ethnically, culturally and linguistically heterogeneous (Cheshire et al. 2011; Kerswill, Torgersen et al. 2008; Fox 2015). For instance, the largest ethnic group in the London Borough of Tower Hamlets is Bangladeshi, representing $32 \%$ of the population, followed by White British who constitute $31 \%$ of the population (Office for National Statistics 2016). High rates of cultural and linguistic heterogeneity have led to the emergence of MLE in the inner-city East London boroughs of Tower Hamlets (Fox 2015) and Hackney, and to a lesser extent, in Havering, an outer-London borough, previously part of Essex (Cheshire et al. 2011; Kerswill, Torgersen et al. 2008).

The emergence of MLE is reflected in several apparent-time changes which have been found in the vowel systems in both Tower Hamlets and Hackney, and to a lesser extent, in

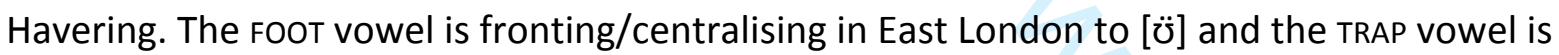
centralising to [ẹ]. This differs from the traditional TRAP Cockney variants $[\varepsilon] \sim[æ]$ which are found in older speakers (Kerswill, Cheshire et al. 2008; Fox, 2015). The STRUT vowel is backing and raising (Kerswill, Cheshire et al. 2008), in contrast with the traditional Cockney STRUT vowel which is fronted and occurs in the region of [e] to [a] (Wells 1982). Although a traditional Cockney GOOSE vowel, [ $\mathrm{H}:$ ], is reported to be slightly more fronted than in Standard Southern British English (SSBE) (Wells 1982), extreme fronting is found amongst younger, non-Anglo speakers in Hackney (Kerswill, Torgersen et al. 2008). However, as FOOT and GOOSE are fronting in many varieties of English in Southeast England, including RP (e.g. 
GOOSE: Harrington, Kleber \& Reubold 2008; FОOT: Fabricius 2007) this arguably should not be considered an MLE feature.

Still larger differences have been found in the diphthong system in East London, in particular for the MOUTH and PRICE vowels. One of the defining phonetic features of Cockney is a diphthong shift, whereby the / $/$-diphthongs are rotated clockwise and the ///-diphthongs show an anti-clockwise movement (Wells 1982; Labov 1994). Thus, the Cockney MOUTH vowel is fronted whilst the PRICE vowel has a backed and raised onset (Wells 1982). The traditional Cockney PRICE vowel is considered to range from a diphthong with a fully backed and raised onset, [ $[\mathrm{I}]$, to one with a lowered onset [aı], and can also be produced as a monophthong, [a:], in broad Cockney (Sivertsen, 1960; Wells, 1982). Cockney MOUTH is described as ranging from a monophthong [æ:] to a closing-backing diphthong [æひ], with a 'true Cockney' producing the former (Wells 1982:309). However, in Hackney, and to a lesser extent, in Havering, the diphthong shift has been reversed (Cheshire et al. 2011). Both PRICE and MOUTH are lowering and centralising. PRICE is produced using the narrow diphthongs [aI] or [eI], or even monophthongal [æ], instead of traditional [al], and the MOUTH vowel is now typically a lowered, mid-front monophthong or an innovative back diphthong [av] (Kerswill, Torgersen et al. 2008; Fox 2015).

Given Debden's geographic proximity to East London, one possibility is that like younger speakers in Havering, younger speakers in Debden will also use MLE features. Another possibility however, is that the variety in Debden will show evidence of dialect levelling, i.e., a reduction of local variants and adoption of supra-regional variants as has been found in other towns in the south-east of England, such as Milton Keynes and Reading (Kerswill \& Williams 2000, 2005; Williams \& Kerswill 1999). Milton Keynes is a new-build town that was 
constructed in the 1960s to ease the over-population of London. Around $75 \%$ of those who lived in Milton Keynes had moved there from other areas in the Southeast, including London. This led to the emergence of a 'new town koine' as a result of dialect levelling (Kerswill \& Williams 2000, 2005). In this variety, whilst older speakers have a traditional Cockney PRICE vowel, young speakers use [aI] which is intermediate between SSBE [aI] and broad London [a:]. The MOUTH vowel most closely resembles SSBE [av] in young speakers, whilst Cockney variants are found in older speakers (Kerswill \& Williams 2000, 2005).

Like Milton Keynes, Debden is a new town (or new estate, in this case) and is on the Greater London periphery. On this basis, we might predict that we may also find evidence of levelling in younger speakers in Debden. However, Debden differs from Milton Keynes in several ways. Firstly, the changes found in Milton Keynes have been linked to limited closeknit social networks in the community (Torgersen \& Kerswill 2004). If a strong sense of community and close-knit networks are found in Debden, this may inhibit change towards SSBE features. Secondly, unlike Milton Keynes, Debden was originally populated almost entirely by one social group; white, working-class East Londoners. These factors may instead promote retention of traditional Cockney features, particularly given the social meaning that may be attached to features in terms of place and identity.

\subsection{Place, identity and indexicality in language change}

Language is a complex, symbolic resource which speakers use to communicate referential information and to signal and negotiate social meaning (Eckert, 2008). 'Indexicality' refers to the ideological relationship between linguistic features and a social group, persona, characteristic or place that they signal (see Silverstein 2003; Eckert 2008; Johnstone et al. 2006; Montgomery \& Moore 2017). In this paper we investigate through both a quantitative 
and qualitative analysis, the indexicality of phonetic features in Debden in terms of their ideological association with place and identity.

Whilst it is possible that young people in Debden have maintained Cockney phonetic features, they may not identify themselves or their way of speaking as 'Cockney'. As previously mentioned, a Cockney is considered to be a person who was born within the Bow Bells and lives in East London. Most people aged under c.70yrs in Debden do not fulfil either of these characteristics and therefore, may not identify themselves or their accent as 'Cockney'. Nonetheless, if we consider 'Cockney' to be a socio-cultural identity, it may be possible for young people in Debden to inherit a Cockney identity through their families and the local community. As Moore and Montgomery explain, place is 'symbolic, socially constructed, and culturally defined, as much as it is physically delimited' (2017: 5). Therefore, although Debden is in Essex, it may be possible that all generations in Debden identify with Cockney and East London due to their Cockney heritage and culture.

The continuation of Cockney culture to Debden may have facilitated both the maintenance of Cockney features and speakers' ideological identification with 'Cockney'. For instance, Debden Broadway houses Kelly's Pie and Mash shop which was originally opened in 1915 in Bethnal Green, East London. The shop serves food which has long been served in East London and is associated with this area, such as jellied eels, pie, mash and liquor. This is in stark opposition to East London where many established food outlets like this have closed. For instance, Tubby Isaacs, a jellied eel stall in Aldgate, closed in 2013 after 94 years. Similarly, in 2019, Cook's Pie and Mash shop announced that they would close in Hackney after over 100 years. Further, in the 1950s, the performing arts group, the 'Loughton Players', was established in Debden. This group became popular in the community and 
mainly performed Music Hall songs which are strongly associated with Cockney music and dance (e.g. the Cockney 'knees up'). Indeed, it has been argued that Essex could now be considered a more authentic example of traditional Cockney culture than East London (Watt et al. 2014). This may also have supported maintenance of a close-knit, relatively homogeneous community which in turn, may mean that Cockney features continue to be used (cf. koineization towards the standard in Milton Keynes: Kerswill \& Williams 2000, 2005; Williams \& Kerswill 1999). This may mean that young people in Debden identify with 'Cockney' both socially and linguistically, despite being born and raised in Essex.

Another possibility though, is that speakers will identify with Essex and not East London. We know that official county borders are important determiners in linguistic production. For instance, Llamas (2007) found that in Middlesbrough, linguistic features changed through generations depending on whether the town was officially considered its own unitary authority or part of the counties Yorkshire, Teeside or Cleveland. Speakers orientated their speech towards the linguistic features of the county in which the town was situated at any given time. Similarly, we may also expect speakers to label their linguistic features in terms of the county where they live. That is, if they are from Essex, they may identify their phonetic features as 'Essex' to ideologically index their origins. In this way then, Debden may differ from Havering. Although geographically, Debden is as close, if not closer, to inner-East London than Havering, since 1964, Debden has fallen under the jurisdiction of Essex whilst Havering is part of Greater London. Therefore, those in Debden may ideologically orientate towards 'Essex' linguistic features and identify their accent as 'Essex', rather than identifying with London and MLE features. 
However, what constitutes an Essex accent is complex and there may be generational differences in how this term is interpreted and used. In the Survey of English Dialects, much of Essex shared linguistic similarities with Suffolk and Norfolk rather than London (Orton 1962). More recently, though, Trudgill has argued that only north-eastern Essex forms part of East Anglian English (Trudgill 2008). Therefore, whilst we may expect older participants to associate an Essex accent with typically East Anglian features, younger speakers are likely to hold different associations. In modern times, an Essex accent may be more readily associated with the way of speaking in the docusoap The Only Way is Essex (TOWIE; ITV) which is mostly filmed in Southwest Essex (e.g. Brentwood and Loughton). TOWIE follows the lives and relationships of young people living in Southwest Essex who speak a variety more linguistically similar to Cockney than East Anglian (see Levon \& Holmes-Elliott 2013). It may be then that for young people, as a result of the importation of Cockney culture to Essex (Watt et al. 2014), Cockney linguistic features and even culture, may be re-interpreted as Essex accent features. This means that young speakers in Debden may have maintained Cockney phonetic features, but that they may associate these with an Essex accent.

Gender may also affect how speakers label their accent. Cockney culture has long been considered matrifocal, characterised by dense social networks of female friends and relatives. Young and Willmott (1957) highlight the negative impact that relocating from East London to Debden had on families and in particular, the wellbeing and happiness of women in Debden. They describe the traditional East End as a place where women are the centre of the community, people live near their female relatives, generations of women raise children together and families pop in and out of each other's houses throughout each day (Young \& Willmott 1957). Although some have criticised the validity of Young and Willmott's claims (e.g. Clapson 1999; Lawrence 2016), in recent times Cohen (2013) replicated their findings in 
the Isle of Dogs, East London. He found that Cockney culture was matrifocal and that a Cockney identity was matrilinear. That is, although young women still identified as Cockney, the erosion of job succession from father to son in dock workers meant young men no longer felt a strong sense of Cockney identity. Similarly, young women in Debden, particularly those who have a close-knit network of female friends and relatives, may maintain a Cockney identity and be more likely to identify their accent as Cockney than young men.

\subsection{This study}

This study investigates phonetic variation and change in the vowel system in relation to place and identity in Debden. Male and female participants in four age groups (14-27yrs, 2855yrs, 56-69yrs and 70yrs+) were recorded completing a sociolinguistic interview in which they read out a wordlist, a short passage and were interviewed about their attitudes towards their accent and identity. We aim to explore (1) the extent to which the Cockney vowel system has been maintained in the context of ongoing linguistic changes in the Southeast, evaluating to what extent the English spoken in Debden can be described as 'Cockney moved east' (Fox 2015), and (2) how the variety/varieties of English spoken in Debden are labelled by speakers and how this relates to the community's sense of place and identity.

\section{Methods}

\section{A. Participants}

Twenty-four male subjects aged 14-90yrs $(M=46 y r s, S D=23.5)$ and 30 female subjects aged 15-91yrs $(M=49.9 y r s, S D=24.9)$ were tested, giving four age groups; $14-27 y r s(n=18$, 
female $=9), 28-55 y r s(n=13$, female $=8), 56-69 y r s ~(n=12$, female $=7)$ and 70yrs $+(n=11$, female=6) .

All participants were either from East London, or their parents or grandparents were. All participants aged 70yrs or over were born in East London, whilst all participants aged 32yrs and younger were born in Debden. This was with the exception of one participant whose parents were from Debden, had moved to another part of the UK but returned when the participant was aged 4yrs. We did not overtly seek to match participants on educational levels. However, of the participants recruited, very few held A levels (qualifications typically taken by school students aged 18yrs) or higher. Of the youngest age group, most had completed GCSEs (qualifications taken at age 16yrs) or BTEC (vocational and work-related course). One participant was currently studying for a degree, and all those aged <19yrs were still in school. No participants in the 28-55yrs age group held qualifications higher than GCSEs with the exception of two participants who held vocational qualifications. All participants over 55yrs had left school aged 13-15yrs except for two participants who had completed O-levels (a qualification pre-dating GCSEs that was also taken at age 16yrs), one participant who had completed a BA degree in her 70s, and two participants who had completed Higher National Certificates in engineering (a UK higher education qualification). All except two participants were living in Debden at the time of the study. One (45yrs, male) had moved aged 12yrs from East London to a neighbouring town. However, his parents owned a business in Debden where he spent a lot of time and where he worked from aged 25yrs. A final participant (24yrs, female), had lived in Debden until the age of 19yrs before moving to a nearby estate where she was offered council housing. 
All participants were white, monolingual English speakers and none reported significant hearing problems, or a history of speech or language difficulties. All participants originated from working-class, London families as ascertained from employment and educational attainment data.

\section{B. Stimuli and apparatus}

Prior to the interview, the participants completed a background questionnaire to elicit basic demographic information as well as an Identity Questionnaire (Llamas 2007) to elicit information about their attitudes towards their language and identity. For each question, participants responded using a 7-item Likert scale, ranging from strongly disagree to strongly agree. The questions which will be considered in this present study asked participants to rank whether they believed they spoke with 1) an Essex accent; 2) an East London accent; 3) a Cockney accent and whether they 4) considered themselves Cockney. All participants completed a sociolinguistic interview (Labov 1966) to elicit speech in a range of different speech styles: a word-list, a phonetically-balanced passage and then an open interview about a wide range of factors including their lives and their experiences of Debden/East London.

The wordlist consisted of /b/-V-/t/ and /b/-V-/d/ words as well as /h/-V-/d/ words covering the majority of the English vowel space. As high frequency words and transparent spelling were important in ensuring that all participants' ability could read the words fluently, we also included some high frequency words which did not fit the /h/-V-/d/ or /b/-V-/d/ format, e.g. mouth, toad, boy. A total of 50 words were included and all participants read each word twice. The reading passage was an adaptation of Chicken Little (Shaw, Best, Docherty, Evans, Foulkes, Hay \& Mulak 2018). Of particular interest were the words 
containing the MOUTH, PRICE, TRAP, STRUT, GOOSE and FOOT Vowels as these show the largest observed changes in modern-day East London speech (e.g. Fox 2015; Cheshire et al. 2011). All recordings were made directly onto a laptop computer with a sampling rate of $44.1 \mathrm{kHz}$, 16-bit resolution using an MXL Studio 1 USB microphone.

\section{Procedure}

Each subject started by producing the reading passage. They were given time to read the passage through to themselves before making their recording, and were asked to repeat sentences with any errors or hesitations. They then recorded the wordlist. They recorded two repetitions of each target word in a randomised order. The words and the passage were presented on PowerPoint on an electronic tablet which the participants controlled themselves. The speakers were instructed to read the words and the passage as if they were talking to a friend or family member. They then completed the interview. All interviews were conducted in 2017 by the primary author, a white, English-speaking female from Debden with heritage in working-class, East London families. Individuals are known to alter the way they speak as a function of their interlocutor (Bell 1984) and so participants were recruited using the friend-of-a-friend approach as it was believed that the researcher's relationship with the subjects would encourage them to speak in a way that they would when communicating with those living in the local area (Milroy 1987). This was of particular importance in the Debden community; nearly all the participants enquired as to her place of heritage and several referred to her as 'one of us' and were thus happy to share their experiences. This method was used with the exception of those aged between $14 \mathrm{yrs}$ and 16yrs who were recruited through their school and took part in the interview in a classroom setting. 
The interview was designed to follow up on a questionnaire which participants had filled in beforehand, and which also solicited basic demographic information. Over 40 hrs of interview data was collected from the 54 participants. The interviews were conducted in the model of linguistic ethnography whereby they were semi-structured, and no set questions were asked to all participants, but instead several themes were discussed such that topics that arose naturally were free to be pursued (Copland \& Creese 2015). Of these interviews, most were completed on a one-to-one basis. Seven interviews were conducted in groups. The participants aged 14-16yrs were interviewed in two separate groups of three. Two interviews consisted of a husband and wife, one interview included a husband, wife, and her father and another two elderly sisters. Two other interviews included groups of friends; one included two female friends and in the other, five elderly women were interviewed together. The results of the interview with the five elderly women was not included as three of the women later agreed to take part in a one-to-one interview with the author and the results of these three interviews were then included in this study.

The majority of recordings took place in a quiet room in the primary author's parents' or participants' homes. Where this was not possible, participants were recorded in a public place, e.g. their workplace, in as quiet an environment as possible. As previously mentioned, those aged 14-16yrs were interviewed in classrooms in their school. The participants were seated at a table or on a sofa with the microphone placed on a table in front of them.

\section{Analysis}

\section{Acoustic analysis}

All acoustic measurements were taken from the vowels produced in both the wordlist and the passage. The wordlist and passage productions were each transcribed in ELAN before 
time-aligned text-grids were produced for each audio file with FAVE align. The text-grids were manually checked and any errors hand corrected. The F1 and F2 measurements at $20 \%, 35 \%, 50 \%, 65 \%$ and $80 \%$ were then extracted and normalised according to the Lobanov method within each speaker with FAVE Extract (Rosenfelder, Fruehwald, Evanini, Seyfarth, Gorman, Prichard \& Yuan 2014). For monophthongs, the F1 and F2 values were analysed at $50 \%$ and for the diphthongs, F1 and F2 measurements were taken at $20 \%$ (onset) and $80 \%$ (offset). For the wordlist, acoustic measurements from both repetitions of each word were included in the analysis. For the passage, acoustic measurements from all vowels in primary stressed syllables were analysed. As FAVE align is based on American English, adjustments were made to some transcriptions to fit SSBE pronunciations. For instance, SSBE is not rhotic, has a TRAP-BATH split, and unlike standard US English, both the LOT and CLOTH vowels correspond to [D] in SSBE. High frequency and function words such as prepositions and pronouns were not included as they are more likely to be reduced. A total of 316 different words were analysed from the passage and the wordlist combined.

Vowel productions were excluded from the analysis if FAVE extract could not produce formant readings of F1 and F2 at any measurement point, for instance, if FAVE had not been able to accurately track formants. Outliers for each vowel, defined as any data points more than 1.5 interquartile ranges (IQRs) below the first quartile or above the third quartile, were also excluded as these were likely formant tracking errors. A total of 13,506 vowel productions were analysed across 54 speakers from 316 different words.

Multiple Linear Regression (MLR) analyses were run to assess potential changes in F1 and F2. For all statistical analyses, $\alpha$ was set at 0.05 . The independent variables in the linear regression analyses were age (categorical: four age groups) and gender, as well as the 
interaction between these two variables. The Likert-scale, identity data were also included as independent variables in order to examine whether, when holding age and gender constant, there was a relationship between phonetic production and identifying with Essex, East London or Cockney accents. The model also controlled for the surrounding phonological environment; manner, place and voicing of both the preceding and following sounds were included in the analyses.

The dependent variable for each analysis was the individual F1 or F2 values. For the diphthongs, individual MLR analyses were run to consider both the onset and glide elements of each vowel. The reference level for gender was 'female' as this constituted the largest group and was thus most likely the most accurate estimate of an effect ( $n=30,55.5 \%$ of data). The reference level for age was the 14-27yrs group ( $n=18,33.3 \%$ of data) as the far end of the scale (i.e., youngest age group), which is the most obvious point of comparison for analysing language change in apparent-time. Vowel plots were produced in $\mathrm{R}$ with the PhonR package (McCloy 2016).

\section{Attitude and identity}

Kruskal Wallis tests investigated potential effects of age and gender on the four attitude and identity questions which asked participants to rate on a Likert scale whether or not they 1) considered themselves to be Cockney; 2) believed they spoke with an Essex accent; 3) believed they spoke with an East London accent; or 4) believed they spoke with a Cockney accent. The Likert scale data was coded as the dependent variable in each of the analyses. Age and gender effects were investigated separately; individual tests investigated age effects within each gender, and gender effects were investigated separately within each age group. 


\section{Qualitative analysis}

All interviews were transcribed using ELAN (Version 5.4) (Nijmegen: Max Planck Institute for Psycholinguistics). Interviews were transcribed in full or up to the first 50 minutes, whichever came first, and points that mentioned a theme relevant for this paper, e.g., a participant's (or the community's) sense of linguistic or social identity in relation to Cockney, East London or Essex, were coded. These sections were then extracted and transcripts were produced. These abridged transcripts were then grouped by gender and age-group. Following this, for each age group and gender, we extracted the general theme that most frequently emerged in the interview. We present the written transcriptions that most clearly capture the key themes that were extracted.

\section{Results}

\section{A. Quantitative vowel analysis}

\section{Monophthongs}

Fig. 2 displays the average F1 \& F2 values of the monophthongs produced by each age group. Whilst there is a great deal of stability in the vowel space, there are also some differences, in particular, in the production of GOOSE, FOOT, STRUT and TRAP. MLR analyses confirmed that the GOOSE $[F(21,280)=6.73)$ and FOOT $(F(18,94)=3.889]$ vowels were significantly more fronted in the 14-27 age group compared to all those aged $>27 y$ rs \& $>55 y$ rs respectively ( $p<0.05$ for all comparisons). The youngest age group were also found to have a significantly lower FOOT vowel than the $28-55 y$ rs age group $[F(18,94)=3.24, p=0.026]$. However, the effect size was very small and there was no significant difference when compared to any other age group (see Fig. 2). 
The TRAP vowel was firstly, lowered $[F(26,316)=3.757]$ in the $14-27 y r s$ age group compared to the 56-69yrs $(p=0.001)$ and 70yrs + groups $(p=0.011)$ and secondly, more backed $[F(26,316)=6.59]$ compared to all other groups $(p<0.05)$. The STRUT vowel was significantly raised $[F(33,775)=6.958]$ in the $14-27 y r s$ age group compared to all other groups and significantly backed compared to the two oldest groups $[F(33,775)=17.72](p<0.01$ for all comparisons).

----- Figure 2 about here -----

There was also a small but significant difference in the NURSE vowel which was lower in the $14-27 y r s$ age group compared to the $56-69 y r s$ age group $[F(22,294)=4.848, p<0.001]$. It was also significantly more backed in the 14-27yrs group compared to the 28-55yrs group $[F(22,294)=11.48, p<0.001]$. However, it was further front than in the $70 y r s+$ group suggesting that there is no systematic, linear change in apparent-time. The LOT vowel was significantly more fronted in the youngest age group when compared to the 70yrs+ group $[F(21,186)=7.09, p=0.02]$ but once again the effect size was small. The DRESS vowel was significantly backed in the youngest age group $[F(34,791)=9.924]$ compared to the $56-69 y$ rs and 70yrs+ age groups ( $p<0.001$ for both). The THOUGHT vowel was also significantly fronted in the youngest age group compared to the $70 y r s+\operatorname{group}[F(32,550)=9.667, p<0.001]$.

There were few significant differences in production according to gender, and these were relatively small (see Fig. 2). The TRAP vowel was more front $[F(5,31)=4.453, p=0.042]$ and raised in men compared to women $[F(26,316)=3.76, p<0.01]$. The THOUGHT $[F(32,550)=9.67$, $p<0.001], \operatorname{KIT}[F(32,489)=8.13, p=0.002]$ and LOT $[F(21,186)=7.09, p=0.002]$ vowels were all backed in men. 
There were several significant interactions between age and gender. For the THOUGHT vowel, there were no gender differences in the 70yrs+ age group but the vowel was lower in men for other age groups. The START vowel was lower in males than females in the 28-55yrs age group but this effect was not found for other age groups $[F(25,166)=1.716, p=0.0379]$. Similarly, contrary to other age groups, the STRUT vowel was lower in men than women in the 56-69yrs group $[F(33,775)=6.958, p<0.001]$, the DRESS vowel was higher for men in the 56-69yrs age group compared to other groups $[F(34,791)=8.24, p<0.001]$ and more backed in the 70yrs+ men $[F(32,55)=5.55, p=0.0015]$. The THOUGHT vowel was backed in men compared to women in the $14-27 y r s$ age group $[F(32,550)=9.67, p<0.001]$, and the LOT vowel was more fronted for men in the 28-55yrs age group $[F(21,186)=7.091, p<0.001]$, but not in any other group. The above differences did not seem to represent any systematic interactions between gender and age, but instead, individual groups patterned in various different ways for individual vowels.

There were some significant effects of identity on phonetic production. A lowered DRESS vowel was significantly more likely in those who did not think they had an East London accent $(p=0.045)$ and did not identify as Cockney $(p<0.001)$. Similarly, those with a lowered NURSE vowel and a backed STRUT vowel were less likely to identify as a Cockney $(p=0.0026$ and $p=0.004$ respectively). A raised FOOT vowel was significantly associated with not identifying with an East London accent $(p=0.003)$. In contrast, a fronted THOUGHT vowel was significantly more likely in those who thought they had an East London accent but was less likely in those who thought they had a Cockney accent ( $p<0.001$ and $p=0.007$ respectively). Finally, a more fronted GOOSE vowel was less likely in those who felt they had an East London accent $(p=0.006)$. 
In general, the features which were found in the youngest age group in Debden (lowered NURSE vowel, backed STRUT vowel, fronted THOUGHT vowel, fronted GOOSE vowel) were also found in those who least associated themselves with a Cockney accent and identity, and to a lesser extent, an East London accent. Nonetheless, there were no significant effects between vowel production and considering one's accent to be an Essex one. This suggests that for both older and younger speakers, perceiving oneself to have an Essex accent is not related to the way in which vowels are produced, whilst traditional Cockney phonetic features are indeed associated with having a 'Cockney' accent.

\section{----- Figure 3 about here -----}

\section{Diphthongs}

Figs 4 and 5 display the average F1-F2 values for each age group and gender respectively. The PRICE onset was significantly lower in the two oldest age groups compared to the 14$27 y r s$ group $[F(23,299)=7.1, p=0.029, p<0.001$ respectively for $56-69 y r s$ and $70 y r s+]$. A lower onset was also significantly associated with a lower likelihood of identifying with either an Essex accent $(p=0.024)$ or an East London accent $(p=0.001)$, as well as with a lower likelihood of identifying as Cockney ( $p=0.006)$. The PRICE offset was raised in the $56-69 y$ rs group compared to the $14-27 y r s$ group $[F(23,299)=4.76, p=0.029]$, but there was no significant difference between the youngest and the oldest group suggesting that this is not indicative of a change in progress. When holding age constant, those with a fronted PRICE onset were less likely to consider they had a Cockney accent $(p=0.002)$ or an Essex accent $(p=0.006)$ but more likely to consider themselves Cockney $(p=0.003)$. However, no change was found along the F2 dimension for this vowel in apparent-time. 
The MOUTH onset was significantly lower and the offset was significantly higher in the 14$27 y r s$ group but only when compared to the $28-55 y$ rs group $[F(24,381)=7.08, p=0.018$; $F(24,381)=3.096, p=0.021$ respectively]. However, compared to all other age groups, the MOUTH onset was significant backed in the 14-27yrs group $[F(24,381)=9.88, p<0.001$ for all groups]. The offset was significantly fronted in the $14-27 y$ rs group compared to the $56-69 y$ rs group $[F(24,381)=5.341, p<0.0001]$ but not when compared to the oldest group.

----- Figure 4 about here -----

No significant gender effects were found for either vowel. There were also no significant interactions between gender and age group with the exception of the F2 values for the MOUTH onset. For this vowel, there was a gender effect for the 14-27yrs group alone; men had a more backed MOUTH onset than women.

----- Figure 5 about here -----

\section{Summary of phonetic changes in apparent-time}

On the whole, Cockney phonetic features have been maintained in the community. All age groups have a raised THOUGHT vowel which is more raised than FOOT. All groups also have a fronted GOOSE vowel (further fronted than both FOOT and NURSE), and somewhat fronted TRAP (sitting not far behind DRESS) and STRUT vowels. In terms of diphthongs, traditional Cockney vowels were also found to some extent in all age groups. For instance, to some extent, all age groups had a backed onset (of varying heights) for PRICE (not far in front of START) and a fronted onset for MOUTH (as front as TRAP). Nonetheless, there is some evidence of change in apparent-time towards SSBE vowels. In the youngest age group (14-27yrs), both TRAP and STRUT are lowering and backing, and in line with widespread changes found in British English, GOOSE and FOOT are fronting. There was no significant change in the F2 dimension for PRICE, 
but the onset is raising, whilst for MOUTH, the onset is lowering and backing and the offset is fronting and raising.

\section{B. Attitude and identity}

Gender effects. No significant gender effects were found for any measure for the 14-27yrs, 28-55yrs or 70yrs+ age groups. In the 56-69yrs group, males were significantly more likely than women to consider themselves as speaking with a Cockney accent $[\times 2(1)=4.03$, $p=0.045]$. However, compared to young men, young women tended to associate more strongly with a Cockney identity and accent (see Fig. 6). Whilst young women did not consider themselves or their accent to be Cockney to the same extent as older and middleaged women, they tended to give a higher rating than young males.

Age effects. For males, older participants were significantly less likely to feel that they had an Essex accent $[\chi 2(3)=7.96, p=0.047]$. Further, 70yrs+ males were significantly more likely than males in the other age groups to consider themselves to have an East London $[\times 2(3)=$ $7.89, p=0.048]$ or a Cockney accent $[\chi 2(3)=14.98, p=0.002]$. Similarly, there was a significant association between age and whether male participants considered themselves to be Cockney $[\chi 2(3)=11.8, p=0.008]$, with older participants more likely to consider themselves to be Cockney. Younger women were more likely than older women to consider that they had an Essex accent, $[\chi 2(3)=10.04, p=0.018]$. However, unlike for male participants, there was no relationship between age and whether female participants considered themselves to be a Cockney, or to have a Cockney or East London accent (see Fig. 6).

\section{Qualitative analysis}


In this section we present the recurrent themes that arose during the interviews as relevant to participants' sense of cultural and linguistic identity in relation to Essex, Cockney and East London.

Older participants on the whole, strongly identified as being Cockney. They also felt that the Cockney culture and dialect, with which they strongly identified, were no longer present in modern-day East London, but were found strongly in Debden:

[1] 77-year-old male

East London's definitely down here. I'm not knocking the foreigners, but East London ain't East London no more. It's all foreigners. I can't go Hackney or where I used to go. I can't talk Cockney. They don't know what you're talking about [...] They definitely don't understand. But down here [in Debden], now and again, I might meet a Cockney.

Participants aged $>28 y r s$ who were born in Essex or who had moved to Essex as children had more complex and varied identities. Most believed that they were to some extent a Cockney, an East Ender and from Essex, and did not see any contradiction in these identities. There was substantial variation within this age group and many exhibited hybrid identities. For instance, a 60-year-old participant who had left London at the age of 3 before moving to Debden, identified as Cockney (5/7 on the Likert scale):

[2] 60-year-old male 
I think because you're from London you want to hold on to what you are. That may sound stupid because I moved out when I was young but that's where I'm from and that's where I always tell people I'm from and I almost make a point of it I think when people are talking. So, I'm obviously quite proud that in the day, back then in 1957, that's where I was born and I'm quite happy with that... I have some pride I come from London, I do. And my family; I know my dad did. I'm definitely more a London guy than an Essex guy. I don't think I want to be an Essex guy, which is strange because I've lived here - lived in these parts for 50 odd years so that may sound strange, but I live here, that's it. And that's where I'm from and that's good enough for me.

In contrast, his 72-year-old cousin who comes from the same Cockney family and left London at the age of 5yrs to live in the same street in Debden did not identify as Cockney (1/7 on the Likert scale), demonstrating the variation within this age group.

Young, male participants unanimously distanced themselves from having a Cockney accent or identity. In spite of acknowledging that their parents and/or grandparents were East Enders/Cockneys, they themselves did not share this identity. A young man whose family strongly identified as Cockney, was asked whether he considered himself Cockney:

[3] 24-year-old male

Definitely not. I would say I'm an Essex boy 
Another young male who was raised in Debden did not share the same sense of identity as his mother, who considers herself Cockney:

[4] 26-year-old male

I'm not Cockney at all. I don't want to say I am. If people think that I'm Cockney then that's their opinion, but I don't want to say I am because I've not been brought up in East London and I've not mixed with the right crowd to say that I'm Cockney... I think Cockney's died out. People that pretend they're Cockney shouldn't say they are when - I mean - their parents and their granddads might be, and I might pick up the odd word or two, or the phrase and stuff like that, but I don't think there is a Cockney any more

Interviewer: So what do you consider yourself?

A bit of in-between really. I'm from Essex, you know, like I've been brought up in Essex, that's where l'd say I'm from.

Despite this, he found it perplexing that people he encountered outside of the area frequently mistook him for an East Londoner.

Although young males rejected having a Cockney identity, there was more variation within young females. Whilst some young females did not believe they were Cockney, others believed they were, and that this identity had been transmitted culturally through their family. In the following dialogue, two young women discuss why they consider themselves Cockney. 
[5] 24 and 22-year-old female friends

A: I honestly couldn't - I honestly couldn't say 'oh that makes someone Cockney'. I couldn't. I think it's just one of those things that you grow up with. It rubs off on you and-

B: You're stuck with it

A: Yeh. It sticks- it sticks with you. It sticks with you. It doesn't leave.

B: Yeh

A: Yeh it don't leave you until you leave it.

Furthermore, in extract [6] below, a 25-year-old woman explains why she identifies strongly as Cockney (6/7 on the Likert scale). Whilst she herself was not from East London, she believes that because her family are from Plaistow, East London, she too can identify as Cockney.

[6] 25-year-old female

Interviewer: So, you think you - so you'd consider yourself a Cockney?

C: Yeh. yeh, definitely. Do you or not?

Interviewer: Consider myself?

C: No, consider me.

Interviewer: Consider you? Yeah, I think if you consider yourself Cockney, you're Cockney. 


\section{C: Cool stuff, cool stuff.}

Interviewer: And what makes someone Cockney?

C: Um, I don't know. They - the Coc- the Cockney accent usually originates from London, don't it? So, someone who's stayed in London or you know, or been around someone that speak a lot of Cockney language from London or-

Interviewer: Yeah, so even though you're not born in London or lived in London you think it'show, like? How could you be Cockney. I'm just sort of curious to see, like.

C: Um, 'cause my family are from Plaistow.

In summary, older generations in London (particularly those aged 70yrs+) did identify as Cockney and believed the way they spoke was 'Cockney'. In contrast, middle-aged generations had hybrid identities between Essex, Cockney and East London which they did not believe was contradictory. A gender difference was found in young participants such that young men unanimously did not identify as Cockney whilst some young women did as they believed they had inherited it from their families.

\section{Discussion and conclusion}

The current study investigated variation and change, and indexicality in the vowel system of the variety spoken in Debden. Overall, the results indicate that on the whole, a Cockney vowel system has been maintained. For instance, all age groups in Debden had traditional Cockney features (Wells 1982) such as a raised THOUGHT, fronted STRUT, and fronted GOOSE vowel, and a backed onset for PRICE and fronted onset for MOUTH. Whilst GOOSE fronting is somewhat hard to interpret due to widespread fronting in many areas of the Southeast (e.g. 
Harrington et al., 2008), it is notable that all age groups have a fronted variant that is further fronted than FOOT, consistent with descriptions of Cockney (Wells 1982). It seems that linguistically, Cockney did move east to Essex (Fox 2015), along with the traditional East End communities who relocated in the Cockney Diaspora (Watt et al. 2014).

There were however, some apparent-time changes in the vowel system. The GOOSE and fOOT vowels were fronting, TRAP was lowering and backing, STRUT was raising and backing, DRESS was backing, THOUGHT was fronting, the PRICE onset was raising and the MOUTH onset was lowering and backing whilst the offset was fronting and raising. The fronting of THOUGHT and lowering and backing of TRAP were more advanced in women. No other gender effects were found suggesting that neither women nor men are leading change. As previously mentioned, the fronting of GOOSE and FOOT is consistent with findings across Southeast England, including in RP (e.g. GOOSE: Harrington et al. 2008; FOOT: Fabricius 2007). Indeed, the vowel system appears to be in the early stages of moving towards SSBE targets like those found in Reading and Milton Keynes (Kerswill \& Williams 2000, 2005). Debden thus differs from Havering where some MLE features have been found in young speakers (Cheshire et al. 2011; Kerswill, Torgersen et al. 2008). Although Debden is geographically as close to inner-East London as Havering, the former is officially in Essex and the latter is in Greater London. One possibility is that this has affected accent variation and change in Debden; young speakers in Debden may look ideologically outwards to the home counties (the counties that immediately surround London) and not inwards to London, with change towards SSBE targets much like that observed in the home counties (Kerswill \& Williams 2000, 2005). 
In general, the features which were found in the youngest age group (lowered NURSE vowel, backed STRUT vowel, fronted THOUGHT vowel, fronted GOOSE vowel) were also found in those who least associated with a Cockney accent and identity, and to a lesser extent, an East London accent and identity. No significant effects between phonetic production and identification with an Essex accent were found. This suggests that for all age groups in Debden, speakers' vowel systems do not index an Essex accent. In contrast, using traditional Cockney variants does indeed seem to index a Cockney accent. In this community then, an Essex accent thus appears not to be as socially meaningful as Cockney which instead, is strongly associated with conservatively Cockney phonetic production.

Although we did not compare the data directly, apparent-time change was not found in Debden to the same extent as in Hackney, Havering (Cheshire et al., 2011; Kerswill, Torgersen et al. 2008), Tower Hamlets (Fox, 2015), Milton Keynes or Reading (Kerswill \& Williams 2000, 2005; Williams \& Kerswill 1999). The maintenance of Cockney features in Debden may be related to the relative separation of Debden from the surrounding area (e.g. separate schools, high street, station), the homogeneity of the migrant community which relocated to Debden in the 1950s (unlike Milton Keynes: Kerswill \& Williams 2000, 2005), and the importation of Cockney culture.

Nonetheless, whilst on the whole, Cockney phonetic features were maintained in Debden, the way in which speakers labelled their accents varied across generations. The results of the quantitative attitudinal analysis as well as the qualitative analysis revealed that association with an East London accent or Cockney accent/identity has decreased in apparent-time, whilst identification with an Essex accent has increased. Identifying oneself and one's accent as 'Cockney' appears to have been lost more rapidly in apparent-time for 
men than women; there were significant differences in these measures between old men and young men, but not between old women and young women. This indicates that there has been substantial generational change in how men identify themselves and their accents, but not for women.

The results of the qualitative analysis also revealed that no young men believed they could inherit a Cockney identity in Debden. Instead, they believed this identity was rooted in a certain culture and time-period such that their parents and grandparents were Cockney but that they could not be. In contrast, some (but not all) young women believed they were Cockney and spoke Cockney, a variety they felt that they had inherited from their families. The three young women who most identified as Cockney all lived in social housing and were not working. At the time of recording, two stated that they were looking for work as a hairdresser or as a barmaid, whilst the other looked after her two young children and was not actively job-hunting. These three female participants all reported having strong relationships and a high degree of contact with their families, particularly their mothers and grandparents. For instance, one young woman reported that she always spoke with her mother at least once, but normally twice a day. In some ways then, the nature of these young women's lives did not differ greatly from the lives of the older female participants when they were young women in East London. The differences between young men and women in identifying as 'Cockney', as well as the variation among young women on this measure could thus be explained through the traditional matrilinear and matrifocal nature of Cockney (Young \& Willmott, 1957). Findings from other London communities support this interpretation. In the Isle of Dogs in East London, Cohen (2013) found that the matrifocal nature of Cockney culture has permitted the transmission of a Cockney identity to some 
young women. However, for men, where identity is accessed through their job, specifically working in the docks which have now closed, the Cockney identity is no longer available.

Whilst some, but not all young women identified their accent as Cockney, they simultaneously considered their accent to be an Essex one. Interestingly, they did not see this as a contradiction. Whilst a traditionally Cockney vowel system has been mostly maintained in Debden, both young men and women believed they had an Essex accent. Traditional Cockney features thus appear to have been re-enregistered as denoting an Essex accent. Therefore, different generations in Debden consider the same linguistic features (traditional Cockney features) to have different labels (Cockney for older speakers, Essex for younger speakers). This suggests that the linguistic labels we use to define different accents or dialects are not static or stable, and that even within the same community, these labels are adopted and interpreted differently.

In summary, Cockney has moved East to Essex (Fox 2015), and the traditional Cockney vowel system is found in Debden, though with some early signs of a shift towards SSBE variants. However, there is a disparity between the phonetic features speakers use and how they define them. This is likely linked to the specific social, cultural and historic makeup of the community. Cockney phonetic features have largely been transposed onto an Essex accent and identity, a change which has been led by women. Further, although a Cockney identity is not available for young men, it is possible for some young women, likely as a result of their lifestyles which are grounded within and reflect the matrifocal nature of Cockney (Young \& Willmott 1957; Cohen 2013). In sum, it seems that social change in the community has driven identity change to a greater extent than it has driven linguistic 
change. Thus, whilst Cockney linguistic traits can be considered to have moved East (Fox 2015), on the whole, a Cockney identity has not.

\section{References}

Abercrombie, Patrick (1944) Greater London Plan (HMSO).

Bell, Allan (1984). Language style as audience design. Language in Society 13(2):145-204.

Carter, Terry (2006). Post-War Loughton 1945-1970. Loughton, England: Loughton and District Historical Society.

Cheshire, Jenny; Fox, Susan; Kerswill, Paul; \& Torgersen, Eivind (2008). Ethnicity, friendship network and social practices as the motor of dialect change: linguistic innovation in London. Sociolinguistica 22:1-23.

Cheshire, Jenny; Kerswill, Paul; Fox, Susan; \& Torgersen, Eivind (2011). Contact, the feature pool and the speech community: the emergence of Multicultural London English. Journal of Sociolinguistics 15:151-196.

Clapson, Mark (1999). Working-class women's experiences of moving to new housing estates in England since 1919. Twentieth Century British History, 10(3): 345-365.

Cohen, Phil (2013). On the Wrong Side of the Track? East London and the Post Olympics. London: Lawrence \& Wishart

Copland, Fiona, \& Creese, Angela (2015). Linguistic ethnography: Collecting, analysing and presenting data. Sage.

Eckert, Penelope (2008). Variation and the indexical field 1. Journal of sociolinguistics. 12(4):453-476. 
Fabricius, Anne (2007). Vowel formants and angle measurements in diachronic sociophonetic studies: FOOT-fronting in RP. In Proceedings of the 16th International Congress of Phonetic Sciences. 1477-1480.

Fox, Susan (2015). The new Cockney: New ethnicities and adolescent speech in the traditional East End of London. Basingstoke: Palgrave Macmillan.

Harrington, Jonathon; Kleber, Felicitas; \& Reubold, Ulrich (2008). Compensation for coarticulation, /u/- fronting, and sound change in standard southern British: An acoustic and perceptual study. The Journal of the Acoustical Society of America 123(5):2825-2835.

Johnstone, Barbara; Andrus, Jennifer; \& Danielson, Andrew (2006). Mobility, indexicality, and the enregisterment of 'Pittsburghese'. Journal of English Linguistics 34(2):77- 104.

Kerswill, Paul, \& Williams, Ann (2000). Creating a new town koine: children and language change in Milton Keynes. Language in Society 29(1):65-115.

Kerswill, Paul \& Williams, Ann (2005). New towns and koineization: Linguistic and social correlates. Linguistics 43:1023-1048.

Kerswill, Paul; Cheshire, Jenny; Fox, Susan; \& Torgersen, Eivind (2008). Linguistic Innovators: The English of adolescents in London. Final report submitted to the Economic and Social Research Council, February 2008.

Kerswill, Paul; Torgersen, Eivind; \& Fox, Susan (2008). Reversing "drift": Innovation and Diffusion in the London Diphthong System. Language Variation and Change 20:451-491. Labov, William (1966). The social stratification of English in New York City. Washington DC: Centre for Applied Linguistics. 
Labov, William (1994). Principles of linguistic change. Volume 1: Internal Factors. Blackwell. Lawrence, Jon (2016). Inventing the 'Traditional Working Class': A Re-analysis of Interview Notes from Young and Willmott's Family and Kinship in East London. The Historical Journal 59(2):567-593.

Levon, Erez, \& Holmes-Elliott, Sophie (2013). East end boys and west end girls:/s/-fronting in Southeast England. University of Pennsylvania Working Papers in Linguistics, 19(2):111-120.

Llamas, Carmen (2007). "A place between places": Language and identities in a border town. Language in Society 36(4):579-604

McCloy, Daniel (2016). phonR: tools for phoneticians and phonologists. R package version $1.0-7$

Milroy, Lesley (1987). Language and Social Networks. Blackwell: Oxford Montgomery, Chris, \& Moore, Emma (2017) Language and a sense of place: Studies in language and region. Cambridge: Cambridge University Press.

Moore, Emma (2010) The Interaction between Social Category and Social Practice:

Explaining was/were variation. Language, Variation \& Change 22(3): 347-371

Moore, Emma, \& Montgomery, Chris (2017). Introduction. In C. Montgomery \& E. Moore (Eds.), Language and a sense of place: Studies in language and region (pp. 1-12). Cambridge: Cambridge University Press. doi:10.1017/9781316162477.002

Nijmegen: Max Planck Institute for Psycholinguistics (2019). ELAN (Version 5.4) [Computer software]. 
Office for National Statistics (2016): 2011 Census aggregate data. UK Data Service (Edition: June 2016).

Orton, Harold (1962). Introduction to the Survey of English Dialects. E.J. Arnold, Leeds.

Powell, W. R. (1956). Loughton: Introduction. In A History of the County of Essex: Volume 4, Ongar Hundred. 110-114. British History Online http://www.british-history.ac.uk/vch/essex/vol4/pp110114 [accessed 11 August 2017]. Rosenfelder, Ingrid; Fruehwald, Josef; Evanini, Keelan; Seyfarth, Scott; Gorman, Kyle; Prichard, Hilary; Yuan, Jiahong (2014). FAVE (Forced Alignment and Vowel Extraction) Program Suite v1.2.2 10.5281/zenodo.22281

Shaw, Jason; Best, Catherine; Docherty, Gerard; Evans, Bronwen; Foulkes, Paul; Hay, Jennifer; \& Mulak, Karen (2018). Resilience of English vowel perception across regional accent variation. Laboratory Phonology. 1868-6354

Silverstein, Michael (2003). Indexical order and the dialectics of sociolinguistic life. Language \& communication. 23(3-4):193-229.

Sivertsen, Eva (1960). Cockney Phonology. Oslo, Oslo University Press.

Torgersen, Eivind, \& Kerswill, Paul (2004). Internal and External Motivation in Phonetic Change: Dialect Levelling Outcomes for an English Vowel shift'. Journal of Sociolinguistics. 8: 23-53.

Trudgill, Peter (2008). The dialect of East Anglia: phonology. In Bernd Kortmann \& Clive Upton (eds.), Varieties of English, 178-193. Mouton de Gruyter. 
Vertovec, Steven (2007). Super-diversity and its implications. Ethnic and Racial Studies 30(6):1024-1054

Watt, Paul; Millington, Gareth; \& Huq, Rupa (2014). East London Mobilities: The ‘Cockney Diaspora' and the remaking of the Essex ethnoscape. In Watt, P. \& Smets, P. (Eds.) Mobilities and neighbourhood belonging in cities and suburbs, pp. 121-144. Palgrave Macmillan UK. Wells, John (1982). Accents of English 2: The British Isles. Cambridge: Cambridge University Press.

Wells, John (1994). The Cockneyfication of RP? In Gunnel Melchers \& Nils-Lennart Johannesson (eds.), Nonstandard varieties of language, 198-205. Stockholm: Almqvist \& Wiksell

Williams, Ann, \& Kerswill, Paul (1999). Dialect levelling: Change and continuity in Milton Keynes, Reading and Hull. In P. Foulkes \& G. Docherty (eds.), Urban voices. Accent studies in the British Isles, 141-162. London: Arnold.

Young, Michael, \& Willmott, Peter (1957). Family and Kinship in East London. London: Routledge and Kegan Paul 


\section{Introduction}

Much recent work on London English has suggested that two separate linguistic processes have displaced or are in the process of displacing the Cockney vernacular; (1) dialect levelling across Southeast England and the London peripheries (Williams \& Kerswill 1999; Kerswill \& Williams 2005; Torgersen \& Kerswill 2004) and (2) the emergence of Multicultural London English (MLE) in the traditional East End of London which has partially diffused to outer London (Cheshire, Kerswill, Fox \& Torgersen 2011; Kerswill, Torgersen \& Fox 2008; Fox 2015). MLE is characterized by contact between the diverse multidialectal and multilingual communities that now make up the majority of the population in the traditional East End of London (cf., Vertovec 2007), and it has been argued that as a result, what we think of as traditional Cockney will be lost within the next 20 years (Cheshire et al. 2011; Fox 2015). However, if linguistic features are not just markers of belonging to a particular place, but also reflect social identity and community affiliation (e.g., Eckert 2008; Moore 2010), it is possible that Cockney may continue to be used in some communities. For example, it has been suggested that Cockney has moved east to Essex (Fox 2015), along with the traditional East End communities who relocated in the 'Cockney Diaspora' (Watt, Millington \& Huq 2014). However, if we understand that place is symbolic and culturally defined (Johnstone, Andrus \& Danielson 2006; Montgomery \& Moore 2017) there may be a disconnect between the phonetic features found in the community and the way they are labelled and categorised. This could mean that communities of East Londoners who now reside in Essex do not identify as Cockney. That is, the Cockney identity may not have moved east with the community. Further, even if Cockney phonetic features are maintained, young people may not label this variety as 'Cockney' as this term is strongly associated with East London (cf. 
Johnstone et al. 2006; Montgomery \& Moore 2017). In this paper, we assess firstly, the extent to which Cockney phonetic features have 'moved east' (Fox 2015) to the Debden Estate in Essex. Secondly, we investigate the way in which linguistic features are used to index place and identity in relation to Debden's specific cultural, social and historical background.

\subsection{Community of interest: The Cockney Diaspora and the Debden Estate}

As well as being the name of a language variety, 'Cockney' is also the name given to a group of people. Traditionally, a Cockney is considered to be an individual who was born within the sound of the Bow Bells in Cheapside, the City of London, and lived in London's traditional East End. However, over the last century, the 'Cockney Diaspora' has seen traditional East London communities relocate to the London peripheries, the home counties and in particular, to Essex (see Fox 2015; Watt, et al. 2014). No single reason led to the mass relocation of traditional, white, working-class East Londoners into Essex. Instead, the 'Cockney Diaspora' emerged as a result of a wide range of inter-related factors such as the deindustrialisation of the East End and the slum clearance programmes which ran between the 1920s and the 1960s (Watt et al. 2014).

The Greater London Plan was part of a series of successive governmental slum clearance programmes which sought to reduce East London's poverty and overcrowding by constructing purpose-built towns and housing estates outside of London (Abercrombie 1944). As part of the Greater London Plan, in 1949, the construction of the Debden Estate (or Debden) began in the town of Loughton, Essex. By 1953, Debden comprised 4,321 homes (Powell 1956) with an estimated population of 15,000 people, almost all of whom were white, working-class East Londoners (Carter 2006). Debden has remained largely 
separate from the surrounding area and has separate schools, high streets, stations, markets and churches from Loughton. Loughton, where Debden is situated, is in the county of Essex, approximately 5 miles from the London border (see Fig. 1).

The town is well connected to central London and is directly connected via the London Underground to London Liverpool Street station in the City of London. Since Debden was constructed, the official geographic delimiters of East London and the neighbouring county of Essex have been re-shaped. Traditionally the term 'East End' covered modern-day Tower Hamlets and southern parts of Hackney (Fox 2015). Nonetheless, the London Government Act 1963 saw the areas that now constitute the boroughs of Waltham Forest, Redbridge, Havering, and Barking and Dagenham transferred from Essex to Greater London. Therefore, there has been an expansion of what could be considered 'East London' or the 'East End'. As shown in Fig. 1, although Loughton is officially outside of the jurisdiction of Greater London and is situated in the county of Essex, it borders East London. Debden is geographically as close (if not closer) to the City of London as several outer-London boroughs, e.g., Havering, where some MLE features have been found in young speakers (Cheshire, Fox, Kerswill \& Torgersen 2008; Cheshire et al. 2011; Kerswill, Torgersen et al. 2008; Kerswill, Cheshire, Fox \& Torgersen 2008).

----- Figure 1 about here -----

\subsection{The linguistic context: language variation and change in the vowel system in}

\section{Southeast England and London}

On a linguistic level, the Cockney vernacular has been described as both innovative and highly stigmatised (e.g., Wells 1982); Wells considered it to be 'overtly despised, but covertly imitated' (Wells, 1994:205). Although Cockney has been traditionally associated with East 
London (Wells 1982; Sivertsen 1960), in modern times, Cockney variants are not typically found among young speakers in East London (Cheshire et al. 2011; Kerswill, Cheshire et al. 2008; Fox 2015). Over the past century, the traditional East End, the area with which Cockney is primarily associated, has undergone a vast transformation. Though the East End has always been a centre for immigration, modern-day East London has become increasingly ethnically, culturally and linguistically heterogeneous (Cheshire et al. 2011; Kerswill, Torgersen et al. 2008; Fox 2015). For instance, the largest ethnic group in the London Borough of Tower Hamlets is Bangladeshi, representing 32\% of the population, followed by White British who constitute $31 \%$ of the population (Office for National Statistics 2016). High rates of cultural and linguistic heterogeneity have led to the emergence of MLE in the inner-city East London boroughs of Tower Hamlets (Fox 2015) and Hackney, and to a lesser extent, in Havering, an outer-London borough, previously part of Essex (Cheshire et al. 2011; Kerswill, Torgersen et al. 2008).

The emergence of MLE is reflected in several apparent-time changes which have been found in the vowel systems in both Tower Hamlets and Hackney, and to a lesser extent, in Havering. The FOOT vowel is fronting/centralising in East London to [ت̈] and the TRAP vowel is centralising to $[\underset{\mathrm{e}}{\mathrm{e}}]$. This differs from the traditional TRAP Cockney variants $[\varepsilon] \sim[æ]$ which are found in older speakers (Kerswill, Cheshire et al. 2008; Fox, 2015). The STRUT vowel is backing and raising (Kerswill, Cheshire et al. 2008), in contrast with the traditional Cockney STRUT vowel which is fronted and occurs in the region of [e] to [a] (Wells 1982). Although a traditional Cockney GOOSE vowel, [ $\mathrm{H:}$ ], is reported to be slightly more fronted than in Standard Southern British English (SSBE) (Wells 1982), extreme fronting is found amongst younger, non-Anglo speakers in Hackney (Kerswill, Torgersen et al. 2008). However, as FOOT and GOOSE are fronting in many varieties of English in Southeast England, including RP (e.g. 
GOOSE: Harrington, Kleber \& Reubold 2008; FOOT: Fabricius 2007) this arguably should not be considered an MLE feature.

Still larger differences have been found in the diphthong system in East London, in particular for the MOUTH and PRICE vowels. One of the defining phonetic features of Cockney is a diphthong shift, whereby the / /-diphthongs are rotated clockwise and the /I/-diphthongs show an anti-clockwise movement (Wells 1982; Labov 1994). Thus, the Cockney MOUTH vowel is fronted whilst the PRICE vowel has a backed and raised onset (Wells 1982). The traditional Cockney PRICE vowel is considered to range from a diphthong with a fully backed and raised onset, [วז], to one with a lowered onset [aI], and can also be produced as a monophthong, [a:], in broad Cockney (Sivertsen, 1960; Wells, 1982). Cockney MOUTH is described as ranging from a monophthong [æ:] to a closing-backing diphthong [æひ], with a 'true Cockney' producing the former (Wells 1982:309). However, in Hackney, and to a lesser extent, in Havering, the diphthong shift has been reversed (Cheshire et al. 2011). Both PRICE and MOUTH are lowering and centralising. PRICE is produced using the narrow diphthongs [aI] or [eI], or even monophthongal [æ], instead of traditional [ar], and the MOUTH vowel is now typically a lowered, mid-front monophthong or an innovative back diphthong [av] (Kerswill, Torgersen et al. 2008; Fox 2015).

Given Debden's geographic proximity to East London, one possibility is that like younger speakers in Havering, younger speakers in Debden will also use MLE features. Another possibility however, is that the variety in Debden will show evidence of dialect levelling, i.e., a reduction of local variants and adoption of supra-regional variants as has been found in other towns in the south-east of England, such as Milton Keynes and Reading (Kerswill \& Williams 2000, 2005; Williams \& Kerswill 1999). Milton Keynes is a new-build town that was 
constructed in the 1960 s to ease the over-population of London. Around $75 \%$ of those who lived in Milton Keynes had moved there from other areas in the Southeast, including London. This led to the emergence of a 'new town koine' as a result of dialect levelling (Kerswill \& Williams 2000, 2005). In this variety, whilst older speakers have a traditional Cockney PRICE vowel, young speakers use [aI] which is intermediate between SSBE [aI] and broad London [a:]. The MOUTH vowel most closely resembles SSBE [av] in young speakers, whilst Cockney variants are found in older speakers (Kerswill \& Williams 2000, 2005).

Like Milton Keynes, Debden is a new town (or new estate, in this case) and is on the Greater London periphery. On this basis, we might predict that we may also find evidence of levelling in younger speakers in Debden. However, Debden differs from Milton Keynes in several ways. Firstly, the changes found in Milton Keynes have been linked to limited closeknit social networks in the community (Torgersen \& Kerswill 2004). If a strong sense of community and close-knit networks are found in Debden, this may inhibit change towards SSBE features. Secondly, unlike Milton Keynes, Debden was originally populated almost entirely by one social group; white, working-class East Londoners. These factors may instead promote retention of traditional Cockney features, particularly given the social meaning that may be attached to features in terms of place and identity.

\subsection{Place, identity and indexicality in language change}

Language is a complex, symbolic resource which speakers use to communicate referential information and to signal and negotiate social meaning (Eckert, 2008). 'Indexicality' refers to the ideological relationship between linguistic features and a social group, persona, characteristic or place that they signal (see Silverstein 2003; Eckert 2008; Johnstone et al. 2006; Montgomery \& Moore 2017). In this paper we investigate through both a quantitative 
and qualitative analysis, the indexicality of phonetic features in Debden in terms of their ideological association with place and identity.

Whilst it is possible that young people in Debden have maintained Cockney phonetic features, they may not identify themselves or their way of speaking as 'Cockney'. As previously mentioned, a Cockney is considered to be a person who was born within the Bow Bells and lives in East London. Most people aged under c.70yrs in Debden do not fulfil either of these characteristics and therefore, may not identify themselves or their accent as 'Cockney'. Nonetheless, if we consider 'Cockney' to be a socio-cultural identity, it may be possible for young people in Debden to inherit a Cockney identity through their families and the local community. As Moore and Montgomery explain, place is 'symbolic, socially constructed, and culturally defined, as much as it is physically delimited' (2017: 5). Therefore, although Debden is in Essex, it may be possible that all generations in Debden identify with Cockney and East London due to their Cockney heritage and culture.

The continuation of Cockney culture to Debden may have facilitated both the maintenance of Cockney features and speakers' ideological identification with 'Cockney'. For instance, Debden Broadway houses Kelly's Pie and Mash shop which was originally opened in 1915 in Bethnal Green, East London. The shop serves food which has long been served in East London and is associated with this area, such as jellied eels, pie, mash and liquor. This is in stark opposition to East London where many established food outlets like this have closed. For instance, Tubby Isaacs, a jellied eel stall in Aldgate, closed in 2013 after 94 years. Similarly, in 2019, Cook's Pie and Mash shop announced that they would close in Hackney after over 100 years. Further, in the 1950s, the performing arts group, the 'Loughton Players', was established in Debden. This group became popular in the community and 
mainly performed Music Hall songs which are strongly associated with Cockney music and dance (e.g. the Cockney 'knees up'). Indeed, it has been argued that Essex could now be considered a more authentic example of traditional Cockney culture than East London (Watt et al. 2014). This may also have supported maintenance of a close-knit, relatively homogeneous community which in turn, may mean that Cockney features continue to be used (cf. koineization towards the standard in Milton Keynes: Kerswill \& Williams 2000, 2005; Williams \& Kerswill 1999). This may mean that young people in Debden identify with 'Cockney' both socially and linguistically, despite being born and raised in Essex.

Another possibility though, is that speakers will identify with Essex and not East London. We know that official county borders are important determiners in linguistic production. For instance, Llamas (2007) found that in Middlesbrough, linguistic features changed through generations depending on whether the town was officially considered its own unitary authority or part of the counties Yorkshire, Teeside or Cleveland. Speakers orientated their speech towards the linguistic features of the county in which the town was situated at any given time. Similarly, we may also expect speakers to label their linguistic features in terms of the county where they live. That is, if they are from Essex, they may identify their phonetic features as 'Essex' to ideologically index their origins. In this way then, Debden may differ from Havering. Although geographically, Debden is as close, if not closer, to inner-East London than Havering, since 1964, Debden has fallen under the jurisdiction of Essex whilst Havering is part of Greater London. Therefore, those in Debden may ideologically orientate towards 'Essex' linguistic features and identify their accent as 'Essex', rather than identifying with London and MLE features. 
However, what constitutes an Essex accent is complex and there may be generational differences in how this term is interpreted and used. In the Survey of English Dialects, much of Essex shared linguistic similarities with Suffolk and Norfolk rather than London (Orton 1962). More recently, though, Trudgill has argued that only north-eastern Essex forms part of East Anglian English (Trudgill 2008). Therefore, whilst we may expect older participants to associate an Essex accent with typically East Anglian features, younger speakers are likely to hold different associations. In modern times, an Essex accent may be more readily associated with the way of speaking in the docusoap The Only Way is Essex (TOWIE; ITV) which is mostly filmed in Southwest Essex (e.g. Brentwood and Loughton). TOWIE follows the lives and relationships of young people living in Southwest Essex who speak a variety more linguistically similar to Cockney than East Anglian (see Levon \& Holmes-Elliott 2013). It may be then that for young people, as a result of the importation of Cockney culture to Essex (Watt et al. 2014), Cockney linguistic features and even culture, may be re-interpreted as Essex accent features. This means that young speakers in Debden may have maintained Cockney phonetic features, but that they may associate these with an Essex accent.

Gender may also affect how speakers label their accent. Cockney culture has long been considered matrifocal, characterised by dense social networks of female friends and relatives. Young and Willmott (1957) highlight the negative impact that relocating from East London to Debden had on families and in particular, the wellbeing and happiness of women in Debden. They describe the traditional East End as a place where women are the centre of the community, people live near their female relatives, generations of women raise children together and families pop in and out of each other's houses throughout each day (Young \& Willmott 1957). Although some have criticised the validity of Young and Willmott's claims (e.g. Clapson 1999; Lawrence 2016), in recent times Cohen (2013) replicated their findings in 
the Isle of Dogs, East London. He found that Cockney culture was matrifocal and that a Cockney identity was matrilinear. That is, although young women still identified as Cockney, the erosion of job succession from father to son in dock workers meant young men no longer felt a strong sense of Cockney identity. Similarly, young women in Debden, particularly those who have a close-knit network of female friends and relatives, may maintain a Cockney identity and be more likely to identify their accent as Cockney than young men.

\subsection{This study}

This study investigates phonetic variation and change in the vowel system in relation to place and identity in Debden. Male and female participants in four age groups (14-27yrs, 2855yrs, 56-69yrs and 70yrs+) were recorded completing a sociolinguistic interview in which they read out a wordlist, a short passage and were interviewed about their attitudes towards their accent and identity. We aim to explore (1) the extent to which the Cockney vowel system has been maintained in the context of ongoing linguistic changes in the Southeast, evaluating to what extent the English spoken in Debden can be described as 'Cockney moved east' (Fox 2015), and (2) how the variety/varieties of English spoken in Debden are labelled by speakers and how this relates to the community's sense of place and identity.

\section{Methods}

\section{A. Participants}

Twenty-four male subjects aged 14-90yrs $(M=46 y r s, S D=23.5)$ and 30 female subjects aged 15-91yrs $(M=49.9 y r s, S D=24.9)$ were tested, giving four age groups; $14-27 y r s(n=18$, 
female = 9), 28-55yrs ( $n=13$, female $=8), 56-69 y r s ~(n=12$, female $=7)$ and 70yrs $(n=11$, female=6).

All participants were either from East London, or their parents or grandparents were. All participants aged 70yrs or over were born in East London, whilst all participants aged 32yrs and younger were born in Debden. This was with the exception of one participant whose parents were from Debden, had moved to another part of the UK but returned when the participant was aged 4yrs. We did not overtly seek to match participants on educational levels. However, of the participants recruited, very few held A levels (qualifications typically taken by school students aged 18yrs) or higher. Of the youngest age group, most had completed GCSEs (qualifications taken at age 16yrs) or BTEC (vocational and work-related course). One participant was currently studying for a degree, and all those aged $<19 y$ ys were still in school. No participants in the 28-55yrs age group held qualifications higher than GCSEs with the exception of two participants who held vocational qualifications. All participants over 55yrs had left school aged 13-15yrs except for two participants who had completed O-levels (a qualification pre-dating GCSEs that was also taken at age 16yrs), one participant who had completed a BA degree in her 70s, and two participants who had completed Higher National Certificates in engineering (a UK higher education qualification). All except two participants were living in Debden at the time of the study. One (45yrs, male) had moved aged 12yrs from East London to a neighbouring town. However, his parents owned a business in Debden where he spent a lot of time and where he worked from aged 25yrs. A final participant (24yrs, female), had lived in Debden until the age of 19yrs before moving to a nearby estate where she was offered council housing. 
All participants were white, monolingual English speakers and none reported significant hearing problems, or a history of speech or language difficulties. All participants originated from working-class, London families as ascertained from employment and educational attainment data.

\section{B. Stimuli and apparatus}

Prior to the interview, the participants completed a background questionnaire to elicit basic demographic information as well as an Identity Questionnaire (Llamas 2007) to elicit information about their attitudes towards their language and identity. For each question, participants responded using a 7-item Likert scale, ranging from strongly disagree to strongly agree. The questions which will be considered in this present study asked participants to rank whether they believed they spoke with 1) an Essex accent; 2) an East London accent; 3) a Cockney accent and whether they 4) considered themselves Cockney. All participants completed a sociolinguistic interview (Labov 1966) to elicit speech in a range of different speech styles: a word-list, a phonetically-balanced passage and then an open interview about a wide range of factors including their lives and their experiences of Debden/East London.

The wordlist consisted of /b/-V-/t/ and /b/-V-/d/ words as well as /h/-V-/d/ words covering the majority of the English vowel space. As high frequency words and transparent spelling were important in ensuring that all participants' ability could read the words fluently, we also included some high frequency words which did not fit the /h/-V-/d/ or /b/-V-/d/ format, e.g. mouth, toad, boy. A total of 50 words were included and all participants read each word twice. The reading passage was an adaptation of Chicken Little (Shaw, Best, Docherty, Evans, Foulkes, Hay \& Mulak 2018). Of particular interest were the words 
containing the MOUTH, PRICE, TRAP, STRUT, GOOSE and FOOT vowels as these show the largest observed changes in modern-day East London speech (e.g. Fox 2015; Cheshire et al. 2011). All recordings were made directly onto a laptop computer with a sampling rate of $44.1 \mathrm{kHz}$, 16-bit resolution using an MXL Studio 1 USB microphone.

\section{Procedure}

Each subject started by producing the reading passage. They were given time to read the passage through to themselves before making their recording, and were asked to repeat sentences with any errors or hesitations. They then recorded the wordlist. They recorded two repetitions of each target word in a randomised order. The words and the passage were presented on PowerPoint on an electronic tablet which the participants controlled themselves. The speakers were instructed to read the words and the passage as if they were talking to a friend or family member. They then completed the interview. All interviews were conducted in 2017 by the primary author, a white, English-speaking female from Debden with heritage in working-class, East London families. Individuals are known to alter the way they speak as a function of their interlocutor (Bell 1984) and so participants were recruited using the friend-of-a-friend approach as it was believed that the researcher's relationship with the subjects would encourage them to speak in a way that they would when communicating with those living in the local area (Milroy 1987). This was of particular importance in the Debden community; nearly all the participants enquired as to her place of heritage and several referred to her as 'one of us' and were thus happy to share their experiences. This method was used with the exception of those aged between 14yrs and 16yrs who were recruited through their school and took part in the interview in a classroom setting. 
The interview was designed to follow up on a questionnaire which participants had filled in beforehand, and which also solicited basic demographic information. Over 40hrs of interview data was collected from the 54 participants. The interviews were conducted in the model of linguistic ethnography whereby they were semi-structured, and no set questions were asked to all participants, but instead several themes were discussed such that topics that arose naturally were free to be pursued (Copland \& Creese 2015). Of these interviews, most were completed on a one-to-one basis. Seven interviews were conducted in groups. The participants aged 14-16yrs were interviewed in two separate groups of three. Two interviews consisted of a husband and wife, one interview included a husband, wife, and her father and another two elderly sisters. Two other interviews included groups of friends; one included two female friends and in the other, five elderly women were interviewed together. The results of the interview with the five elderly women was not included as three of the women later agreed to take part in a one-to-one interview with the author and the results of these three interviews were then included in this study.

The majority of recordings took place in a quiet room in the primary author's parents' or participants' homes. Where this was not possible, participants were recorded in a public place, e.g. their workplace, in as quiet an environment as possible. As previously mentioned, those aged 14-16yrs were interviewed in classrooms in their school. The participants were seated at a table or on a sofa with the microphone placed on a table in front of them.

\section{Analysis}

\section{Acoustic analysis}

All acoustic measurements were taken from the vowels produced in both the wordlist and the passage. The wordlist and passage productions were each transcribed in ELAN before 
time-aligned text-grids were produced for each audio file with FAVE align. The text-grids were manually checked and any errors hand corrected. The F1 and F2 measurements at $20 \%, 35 \%, 50 \%, 65 \%$ and $80 \%$ were then extracted and normalised according to the Lobanov method within each speaker with FAVE Extract (Rosenfelder, Fruehwald, Evanini, Seyfarth, Gorman, Prichard \& Yuan 2014). For monophthongs, the F1 and F2 values were analysed at $50 \%$ and for the diphthongs, F1 and F2 measurements were taken at $20 \%$ (onset) and $80 \%$ (offset). For the wordlist, acoustic measurements from both repetitions of each word were included in the analysis. For the passage, acoustic measurements from all vowels in primary stressed syllables were analysed. As FAVE align is based on American English, adjustments were made to some transcriptions to fit SSBE pronunciations. For instance, SSBE is not rhotic, has a TRAP-BATH split, and unlike standard US English, both the LOT and CLOTH vowels correspond to [p] in SSBE. High frequency and function words such as prepositions and pronouns were not included as they are more likely to be reduced. A total of 316 different words were analysed from the passage and the wordlist combined.

Vowel productions were excluded from the analysis if FAVE extract could not produce formant readings of F1 and F2 at any measurement point, for instance, if FAVE had not been able to accurately track formants. Outliers for each vowel, defined as any data points more than 1.5 interquartile ranges (IQRs) below the first quartile or above the third quartile, were also excluded as these were likely formant tracking errors. A total of 13,506 vowel productions were analysed across 54 speakers from 316 different words.

Multiple Linear Regression (MLR) analyses were run to assess potential changes in F1 and F2. For all statistical analyses, $\alpha$ was set at 0.05 . The independent variables in the linear regression analyses were age (categorical: four age groups) and gender, as well as the 
interaction between these two variables. The Likert-scale, identity data were also included as independent variables in order to examine whether, when holding age and gender constant, there was a relationship between phonetic production and identifying with Essex, East London or Cockney accents. The model also controlled for the surrounding phonological environment; manner, place and voicing of both the preceding and following sounds were included in the analyses.

The dependent variable for each analysis was the individual F1 or F2 values. For the diphthongs, individual MLR analyses were run to consider both the onset and glide elements of each vowel. The reference level for gender was 'female' as this constituted the largest group and was thus most likely the most accurate estimate of an effect ( $n=30,55.5 \%$ of data). The reference level for age was the $14-27 y$ rs group ( $n=18,33.3 \%$ of data) as the far end of the scale (i.e., youngest age group), which is the most obvious point of comparison for analysing language change in apparent-time. Vowel plots were produced in $\mathrm{R}$ with the PhonR package (McCloy 2016).

\section{Attitude and identity}

Kruskal Wallis tests investigated potential effects of age and gender on the four attitude and identity questions which asked participants to rate on a Likert scale whether or not they 1) considered themselves to be Cockney; 2) believed they spoke with an Essex accent; 3) believed they spoke with an East London accent; or 4) believed they spoke with a Cockney accent. The Likert scale data was coded as the dependent variable in each of the analyses. Age and gender effects were investigated separately; individual tests investigated age effects within each gender, and gender effects were investigated separately within each age group. 


\section{Qualitative analysis}

All interviews were transcribed using ELAN (Version 5.4) (Nijmegen: Max Planck Institute for Psycholinguistics). Interviews were transcribed in full or up to the first 50 minutes, whichever came first, and points that mentioned a theme relevant for this paper, e.g., a participant's (or the community's) sense of linguistic or social identity in relation to Cockney, East London or Essex, were coded. These sections were then extracted and transcripts were produced. These abridged transcripts were then grouped by gender and age-group. Following this, for each age group and gender, we extracted the general theme that most frequently emerged in the interview. We present the written transcriptions that most clearly capture the key themes that were extracted.

\section{Results}

\section{A. Quantitative vowel analysis}

\section{Monophthongs}

Fig. 2 displays the average F1 \& F2 values of the monophthongs produced by each age group. Whilst there is a great deal of stability in the vowel space, there are also some differences, in particular, in the production of GOOSE, FOOT, STRUT and TRAP. MLR analyses confirmed that the GOOSE $[F(21,280)=6.73)$ and FOOT $(F(18,94)=3.889]$ vowels were significantly more fronted in the 14-27 age group compared to all those aged $>27 y$ rs \& $>55 y$ rs respectively ( $p<0.05$ for all comparisons). The youngest age group were also found to have a significantly lower FOOT vowel than the 28-55yrs age group $[F(18,94)=3.24, p=0.026]$. However, the effect size was very small and there was no significant difference when compared to any other age group (see Fig. 2). 
The TRAP vowel was firstly, lowered $[F(26,316)=3.757]$ in the 14-27yrs age group compared to the 56-69yrs $(p=0.001)$ and 70yrs + groups $(p=0.011)$ and secondly, more backed $[F(26,316)=6.59]$ compared to all other groups $(p<0.05)$. The STRUT vowel was significantly raised $[F(33,775)=6.958]$ in the $14-27 y r s$ age group compared to all other groups and significantly backed compared to the two oldest groups $[F(33,775)=17.72](p<0.01$ for all comparisons).

----- Figure 2 about here -----

There was also a small but significant difference in the NURSE vowel which was lower in the $14-27 y r s$ age group compared to the $56-69 y r s$ age group $[F(22,294)=4.848, p<0.001]$. It was also significantly more backed in the $14-27 y$ rs group compared to the $28-55 y r s$ group $[F(22,294)=11.48, p<0.001]$. However, it was further front than in the 70yrs+ group suggesting that there is no systematic, linear change in apparent-time. The LOT vowel was significantly more fronted in the youngest age group when compared to the 70yrs+ group $[F(21,186)=7.09, p=0.02]$ but once again the effect size was small. The DRESS vowel was significantly backed in the youngest age group $[F(34,791)=9.924]$ compared to the 56-69yrs and 70yrs+ age groups ( $p<0.001$ for both). The THOUGHT vowel was also significantly fronted in the youngest age group compared to the $70 y r s+\operatorname{group}[F(32,550)=9.667, p<0.001]$.

There were few significant differences in production according to gender, and these were relatively small (see Fig. 2 ). The TRAP vowel was more front $[F(5,31)=4.453, p=0.042]$ and raised in men compared to women $[F(26,316)=3.76, p<0.01]$. The THOUGHT $[F(32,550)=9.67$, $p<0.001], \operatorname{KIT}[F(32,489)=8.13, p=0.002]$ and LOT $[F(21,186)=7.09, p=0.002]$ vowels were all backed in men. 
There were several significant interactions between age and gender. For the THOUGHT vowel, there were no gender differences in the 70yrs+ age group but the vowel was lower in men for other age groups. The START vowel was lower in males than females in the 28 -55yrs age group but this effect was not found for other age groups $[F(25,166)=1.716, p=0.0379]$. Similarly, contrary to other age groups, the STRUT vowel was lower in men than women in the 56-69yrs group $[F(33,775)=6.958, p<0.001]$, the DRESS vowel was higher for men in the 56-69yrs age group compared to other groups $[F(34,791)=8.24, p<0.001]$ and more backed in the 70yrs+ men $[F(32,55)=5.55, p=0.0015]$. The THOUGHT vowel was backed in men compared to women in the $14-27 y r s$ age group $[F(32,550)=9.67, p<0.001]$, and the LOT vowel was more fronted for men in the 28-55yrs age group $[F(21,186)=7.091, p<0.001]$, but not in any other group. The above differences did not seem to represent any systematic interactions between gender and age, but instead, individual groups patterned in various different ways for individual vowels.

There were some significant effects of identity on phonetic production. A lowered DRESS vowel was significantly more likely in those who did not think they had an East London accent $(p=0.045)$ and did not identify as Cockney $(p<0.001)$. Similarly, those with a lowered NURSE vowel and a backed STRUT vowel were less likely to identify as a Cockney $(p=0.0026$ and $p=0.004$ respectively). A raised FOOT vowel was significantly associated with not identifying with an East London accent ( $p=0.003)$. In contrast, a fronted THOUGHT vowel was significantly more likely in those who thought they had an East London accent but was less likely in those who thought they had a Cockney accent ( $p<0.001$ and $p=0.007$ respectively). Finally, a more fronted GOOSE vowel was less likely in those who felt they had an East London accent $(p=0.006)$. 
In general, the features which were found in the youngest age group in Debden (lowered NURSE vowel, backed STRUT vowel, fronted THOUGHT vowel, fronted GOOSE vowel) were also found in those who least associated themselves with a Cockney accent and identity, and to a lesser extent, an East London accent. Nonetheless, there were no significant effects between vowel production and considering one's accent to be an Essex one. This suggests that for both older and younger speakers, perceiving oneself to have an Essex accent is not related to the way in which vowels are produced, whilst traditional Cockney phonetic features are indeed associated with having a 'Cockney' accent.

Figure 3 about here -----

\section{Diphthongs}

Figs 4 and 5 display the average F1-F2 values for each age group and gender respectively. The PRICE onset was significantly lower in the two oldest age groups compared to the 1427 yrs group $[F(23,299)=7.1, p=0.029, p<0.001$ respectively for $56-69 y r s$ and $70 y r s+]$. A lower onset was also significantly associated with a lower likelihood of identifying with either an Essex accent $(p=0.024)$ or an East London accent $(p=0.001)$, as well as with a lower likelihood of identifying as Cockney $(p=0.006)$. The PRICE offset was raised in the 56-69yrs group compared to the $14-27 y r s$ group $[F(23,299)=4.76, p=0.029]$, but there was no significant difference between the youngest and the oldest group suggesting that this is not indicative of a change in progress. When holding age constant, those with a fronted PRICE onset were less likely to consider they had a Cockney accent $(p=0.002)$ or an Essex accent $(p=0.006)$ but more likely to consider themselves Cockney $(p=0.003)$. However, no change was found along the F2 dimension for this vowel in apparent-time. 
The MOUTH onset was significantly lower and the offset was significantly higher in the 14$27 y r s$ group but only when compared to the $28-55 y$ rs group $[F(24,381)=7.08, p=0.018$; $F(24,381)=3.096, p=0.021$ respectively]. However, compared to all other age groups, the MOUTH onset was significant backed in the 14-27yrs group $[F(24,381)=9.88, p<0.001$ for all groups]. The offset was significantly fronted in the 14-27yrs group compared to the 56-69yrs group $[F(24,381)=5.341, p<0.0001]$ but not when compared to the oldest group.

----- Figure 4 about here -----

No significant gender effects were found for either vowel. There were also no significant interactions between gender and age group with the exception of the F2 values for the MOUTH onset. For this vowel, there was a gender effect for the 14-27yrs group alone; men had a more backed MOUTH onset than women.

----- Figure 5 about here -----

\section{Summary of phonetic changes in apparent-time}

On the whole, Cockney phonetic features have been maintained in the community. All age groups have a raised THOUGHT vowel which is more raised than FOOT. All groups also have a fronted GOOSE vowel (further fronted than both FOOT and NURSE), and somewhat fronted TRAP (sitting not far behind DRESS) and STRUT vowels. In terms of diphthongs, traditional Cockney vowels were also found to some extent in all age groups. For instance, to some extent, all age groups had a backed onset (of varying heights) for PRICE (not far in front of START) and a fronted onset for MOUTH (as front as TRAP). Nonetheless, there is some evidence of change in apparent-time towards SSBE vowels. In the youngest age group (14-27yrs), both TRAP and STRUT are lowering and backing, and in line with widespread changes found in British English, GOOSE and FOOT are fronting. There was no significant change in the F2 dimension for PRICE, 
but the onset is raising, whilst for MOUTH, the onset is lowering and backing and the offset is fronting and raising.

\section{B. Attitude and identity}

Gender effects. No significant gender effects were found for any measure for the 14-27yrs, 28-55yrs or 70yrs+ age groups. In the 56-69yrs group, males were significantly more likely than women to consider themselves as speaking with a Cockney accent $[\times 2(1)=4.03$, $p=0.045]$. However, compared to young men, young women tended to associate more strongly with a Cockney identity and accent (see Fig. 6). Whilst young women did not consider themselves or their accent to be Cockney to the same extent as older and middleaged women, they tended to give a higher rating than young males.

Age effects. For males, older participants were significantly less likely to feel that they had an Essex accent $[\chi 2(3)=7.96, p=0.047]$. Further, 70yrs+ males were significantly more likely than males in the other age groups to consider themselves to have an East London $[\chi 2(3)=$ 7.89, $p=0.048]$ or a Cockney accent $[\chi 2(3)=14.98, p=0.002]$. Similarly, there was a significant association between age and whether male participants considered themselves to be Cockney $[\chi 2(3)=11.8, p=0.008]$, with older participants more likely to consider themselves to be Cockney. Younger women were more likely than older women to consider that they had an Essex accent, $[\chi 2(3)=10.04, p=0.018]$. However, unlike for male participants, there was no relationship between age and whether female participants considered themselves to be a Cockney, or to have a Cockney or East London accent (see Fig. 6).

----- Figure 6 about here -----

\section{Qualitative analysis}


In this section we present the recurrent themes that arose during the interviews as relevant to participants' sense of cultural and linguistic identity in relation to Essex, Cockney and East London.

Older participants on the whole, strongly identified as being Cockney. They also felt that the Cockney culture and dialect, with which they strongly identified, were no longer present in modern-day East London, but were found strongly in Debden:

\section{[1] 77-year-old male}

East London's definitely down here. I'm not knocking the foreigners, but East London ain't East London no more. It's all foreigners. I can't go Hackney or where I used to go. I can't talk Cockney. They don't know what you're talking about [...] They definitely don't understand. But down here [in Debden], now and again, I might meet a Cockney.

Participants aged $>28 y$ rs who were born in Essex or who had moved to Essex as children had more complex and varied identities. Most believed that they were to some extent a Cockney, an East Ender and from Essex, and did not see any contradiction in these identities. There was substantial variation within this age group and many exhibited hybrid identities. For instance, a 60-year-old participant who had left London at the age of 3 before moving to Debden, identified as Cockney (5/7 on the Likert scale):

[2] 60-year-old male 
I think because you're from London you want to hold on to what you are. That may sound stupid because I moved out when I was young but that's where I'm from and that's where I always tell people I'm from and I almost make a point of it I think when people are talking. So, I'm obviously quite proud that in the day, back then in 1957, that's where I was born and I'm quite happy with that... I have some pride I come from London, I do. And my family; I know my dad did. I'm definitely more a London guy than an Essex guy. I don't think I want to be an Essex guy, which is strange because I've lived here - lived in these parts for 50 odd years so that may sound strange, but I live here, that's it. And that's where I'm from and that's good enough for me.

In contrast, his 72-year-old cousin who comes from the same Cockney family and left London at the age of $5 y$ rs to live in the same street in Debden did not identify as Cockney (1/7 on the Likert scale), demonstrating the variation within this age group.

Young, male participants unanimously distanced themselves from having a Cockney accent or identity. In spite of acknowledging that their parents and/or grandparents were East Enders/Cockneys, they themselves did not share this identity. A young man whose family strongly identified as Cockney, was asked whether he considered himself Cockney:

[3] 24-year-old male

Definitely not. I would say I'm an Essex boy 
Another young male who was raised in Debden did not share the same sense of identity as his mother, who considers herself Cockney:

\section{[4] 26-year-old male}

I'm not Cockney at all. I don't want to say I am. If people think that I'm Cockney then that's their opinion, but I don't want to say I am because l've not been brought up in East London and I've not mixed with the right crowd to say that I'm Cockney... I think Cockney's died out. People that pretend they're Cockney shouldn't say they are when - I mean - their parents and their granddads might be, and I might pick up the odd word or two, or the phrase and stuff like that, but I don't think there is a Cockney any more

Interviewer: So what do you consider yourself?

A bit of in-between really. I'm from Essex, you know, like I've been brought up in Essex, that's where I'd say I'm from.

Despite this, he found it perplexing that people he encountered outside of the area frequently mistook him for an East Londoner.

Although young males rejected having a Cockney identity, there was more variation within young females. Whilst some young females did not believe they were Cockney, others believed they were, and that this identity had been transmitted culturally through their family. In the following dialogue, two young women discuss why they consider themselves Cockney. 
[5] 24 and 22-year-old female friends

A: I honestly couldn't - I honestly couldn't say 'oh that makes someone Cockney'. I couldn't. I think it's just one of those things that you grow up with. It rubs off on you and-

B: You're stuck with it

A: Yeh. It sticks- it sticks with you. It sticks with you. It doesn't leave.

B: Yeh

A: Yeh it don't leave you until you leave it.

Furthermore, in extract [6] below, a 25-year-old woman explains why she identifies strongly as Cockney (6/7 on the Likert scale). Whilst she herself was not from East London, she believes that because her family are from Plaistow, East London, she too can identify as Cockney.

[6] 25-year-old female

Interviewer: So, you think you - so you'd consider yourself a Cockney?

C: Yeh. yeh, definitely. Do you or not?

Interviewer: Consider myself?

C: No, consider me.

Interviewer: Consider you? Yeah, I think if you consider yourself Cockney, you're Cockney. 


\section{C: Cool stuff, cool stuff.}

Interviewer: And what makes someone Cockney?

C: Um, I don't know. They - the Coc- the Cockney accent usually originates from London, don't it? So, someone who's stayed in London or you know, or been around someone that speak a lot of Cockney language from London or -

Interviewer: Yeah, so even though you're not born in London or lived in London you think it'show, like? How could you be Cockney. I'm just sort of curious to see, like.

C: Um, 'cause my family are from Plaistow.

In summary, older generations in London (particularly those aged 70yrs+) did identify as Cockney and believed the way they spoke was 'Cockney'. In contrast, middle-aged generations had hybrid identities between Essex, Cockney and East London which they did not believe was contradictory. A gender difference was found in young participants such that young men unanimously did not identify as Cockney whilst some young women did as they believed they had inherited it from their families.

\section{Discussion and conclusion}

The current study investigated variation and change, and indexicality in the vowel system of the variety spoken in Debden. Overall, the results indicate that on the whole, a Cockney vowel system has been maintained. For instance, all age groups in Debden had traditional Cockney features (Wells 1982) such as a raised THOUGHT, fronted STRUT, and fronted GOOSE vowel, and a backed onset for PRICE and fronted onset for MOUTH. Whilst GOOSE fronting is somewhat hard to interpret due to widespread fronting in many areas of the Southeast (e.g. 
Harrington et al., 2008), it is notable that all age groups have a fronted variant that is further fronted than FOOT, consistent with descriptions of Cockney (Wells 1982). It seems that linguistically, Cockney did move east to Essex (Fox 2015), along with the traditional East End communities who relocated in the Cockney Diaspora (Watt et al. 2014).

There were however, some apparent-time changes in the vowel system. The GOOSE and FOOT vowels were fronting, TRAP was lowering and backing, STRUT was raising and backing, DRESS was backing, THOUGHT was fronting, the PRICE onset was raising and the MOUTH onset was lowering and backing whilst the offset was fronting and raising. The fronting of THOUGHT and lowering and backing of TRAP were more advanced in women. No other gender effects were found suggesting that neither women nor men are leading change. As previously mentioned, the fronting of GOOSE and FOOT is consistent with findings across Southeast England, including in RP (e.g. GOOSE: Harrington et al. 2008; FОOT: Fabricius 2007). Indeed, the vowel system appears to be in the early stages of moving towards SSBE targets like those found in Reading and Milton Keynes (Kerswill \& Williams 2000, 2005). Debden thus differs from Havering where some MLE features have been found in young speakers (Cheshire et al. 2011; Kerswill, Torgersen et al. 2008). Although Debden is geographically as close to inner-East London as Havering, the former is officially in Essex and the latter is in Greater London. One possibility is that this has affected accent variation and change in Debden; young speakers in Debden may look ideologically outwards to the home counties (the counties that immediately surround London) and not inwards to London, with change towards SSBE targets much like that observed in the home counties (Kerswill \& Williams 2000, 2005). 
In general, the features which were found in the youngest age group (lowered NURSE vowel, backed STRUT Vowel, fronted THOUGHT vowel, fronted GOOSE vowel) were also found in those who least associated with a Cockney accent and identity, and to a lesser extent, an East London accent and identity. No significant effects between phonetic production and identification with an Essex accent were found. This suggests that for all age groups in Debden, speakers' vowel systems do not index an Essex accent. In contrast, using traditional Cockney variants does indeed seem to index a Cockney accent. In this community then, an Essex accent thus appears not to be as socially meaningful as Cockney which instead, is strongly associated with conservatively Cockney phonetic production.

Although we did not compare the data directly, apparent-time change was not found in Debden to the same extent as in Hackney, Havering (Cheshire et al., 2011; Kerswill, Torgersen et al. 2008), Tower Hamlets (Fox, 2015), Milton Keynes or Reading (Kerswill \& Williams 2000, 2005; Williams \& Kerswill 1999). The maintenance of Cockney features in Debden may be related to the relative separation of Debden from the surrounding area (e.g. separate schools, high street, station), the homogeneity of the migrant community which relocated to Debden in the 1950s (unlike Milton Keynes: Kerswill \& Williams 2000, 2005), and the importation of Cockney culture.

Nonetheless, whilst on the whole, Cockney phonetic features were maintained in Debden, the way in which speakers labelled their accents varied across generations. The results of the quantitative attitudinal analysis as well as the qualitative analysis revealed that association with an East London accent or Cockney accent/identity has decreased in apparent-time, whilst identification with an Essex accent has increased. Identifying oneself and one's accent as 'Cockney' appears to have been lost more rapidly in apparent-time for 
men than women; there were significant differences in these measures between old men and young men, but not between old women and young women. This indicates that there has been substantial generational change in how men identify themselves and their accents, but not for women.

The results of the qualitative analysis also revealed that no young men believed they could inherit a Cockney identity in Debden. Instead, they believed this identity was rooted in a certain culture and time-period such that their parents and grandparents were Cockney but that they could not be. In contrast, some (but not all) young women believed they were Cockney and spoke Cockney, a variety they felt that they had inherited from their families. The three young women who most identified as Cockney all lived in social housing and were not working. At the time of recording, two stated that they were looking for work as a hairdresser or as a barmaid, whilst the other looked after her two young children and was not actively job-hunting. These three female participants all reported having strong relationships and a high degree of contact with their families, particularly their mothers and grandparents. For instance, one young woman reported that she always spoke with her mother at least once, but normally twice a day. In some ways then, the nature of these young women's lives did not differ greatly from the lives of the older female participants when they were young women in East London. The differences between young men and women in identifying as 'Cockney', as well as the variation among young women on this measure could thus be explained through the traditional matrilinear and matrifocal nature of Cockney (Young \& Willmott, 1957). Findings from other London communities support this interpretation. In the Isle of Dogs in East London, Cohen (2013) found that the matrifocal nature of Cockney culture has permitted the transmission of a Cockney identity to some 
young women. However, for men, where identity is accessed through their job, specifically working in the docks which have now closed, the Cockney identity is no longer available.

Whilst some, but not all young women identified their accent as Cockney, they simultaneously considered their accent to be an Essex one. Interestingly, they did not see this as a contradiction. Whilst a traditionally Cockney vowel system has been mostly maintained in Debden, both young men and women believed they had an Essex accent. Traditional Cockney features thus appear to have been re-enregistered as denoting an Essex accent. Therefore, different generations in Debden consider the same linguistic features (traditional Cockney features) to have different labels (Cockney for older speakers, Essex for younger speakers). This suggests that the linguistic labels we use to define different accents or dialects are not static or stable, and that even within the same community, these labels are adopted and interpreted differently.

In summary, Cockney has moved East to Essex (Fox 2015), and the traditional Cockney vowel system is found in Debden, though with some early signs of a shift towards SSBE variants. However, there is a disparity between the phonetic features speakers use and how they define them. This is likely linked to the specific social, cultural and historic makeup of the community. Cockney phonetic features have largely been transposed onto an Essex accent and identity, a change which has been led by women. Further, although a Cockney identity is not available for young men, it is possible for some young women, likely as a result of their lifestyles which are grounded within and reflect the matrifocal nature of Cockney (Young \& Willmott 1957; Cohen 2013). In sum, it seems that social change in the community has driven identity change to a greater extent than it has driven linguistic 
change. Thus, whilst Cockney linguistic traits can be considered to have moved East (Fox 2015), on the whole, a Cockney identity has not.

\section{References}

Abercrombie, Patrick (1944) Greater London Plan (HMSO).

Bell, Allan (1984). Language style as audience design. Language in Society 13(2):145-204.

Carter, Terry (2006). Post-War Loughton 1945-1970. Loughton, England: Loughton and District Historical Society.

Cheshire, Jenny; Fox, Susan; Kerswill, Paul; \& Torgersen, Eivind (2008). Ethnicity, friendship network and social practices as the motor of dialect change: linguistic innovation in London. Sociolinguistica 22:1-23.

Cheshire, Jenny; Kerswill, Paul; Fox, Susan; \& Torgersen, Eivind (2011). Contact, the feature pool and the speech community: the emergence of Multicultural London English. Journal of Sociolinguistics 15:151-196.

Clapson, Mark (1999). Working-class women's experiences of moving to new housing estates in England since 1919. Twentieth Century British History, 10(3): 345-365.

Cohen, Phil (2013). On the Wrong Side of the Track? East London and the Post Olympics. London: Lawrence \& Wishart

Copland, Fiona, \& Creese, Angela (2015). Linguistic ethnography: Collecting, analysing and presenting data. Sage.

Eckert, Penelope (2008). Variation and the indexical field 1. Journal of sociolinguistics. $12(4): 453-476$. 
Fabricius, Anne (2007). Vowel formants and angle measurements in diachronic sociophonetic studies: FOOT-fronting in RP. In Proceedings of the 16th International Congress of Phonetic Sciences. 1477-1480.

Fox, Susan (2015). The new Cockney: New ethnicities and adolescent speech in the traditional East End of London. Basingstoke: Palgrave Macmillan.

Harrington, Jonathon; Kleber, Felicitas; \& Reubold, Ulrich (2008). Compensation for coarticulation, /u/- fronting, and sound change in standard southern British: An acoustic and perceptual study. The Journal of the Acoustical Society of America 123(5):2825-2835.

Johnstone, Barbara; Andrus, Jennifer; \& Danielson, Andrew (2006). Mobility, indexicality, and the enregisterment of 'Pittsburghese'. Journal of English Linguistics 34(2):77- 104.

Kerswill, Paul, \& Williams, Ann (2000). Creating a new town koine: children and language change in Milton Keynes. Language in Society 29(1):65-115.

Kerswill, Paul \& Williams, Ann (2005). New towns and koineization: Linguistic and social correlates. Linguistics 43:1023-1048.

Kerswill, Paul; Cheshire, Jenny; Fox, Susan; \& Torgersen, Eivind (2008). Linguistic Innovators: The English of adolescents in London. Final report submitted to the Economic and Social Research Council, February 2008.

Kerswill, Paul; Torgersen, Eivind; \& Fox, Susan (2008). Reversing "drift": Innovation and Diffusion in the London Diphthong System. Language Variation and Change 20:451-491.

Labov, William (1966). The social stratification of English in New York City. Washington DC: Centre for Applied Linguistics. 
Labov, William (1994). Principles of linguistic change. Volume 1: Internal Factors. Blackwell. Lawrence, Jon (2016). Inventing the 'Traditional Working Class': A Re-analysis of Interview Notes from Young and Willmott's Family and Kinship in East London. The Historical Journal 59(2):567-593.

Levon, Erez, \& Holmes-Elliott, Sophie (2013). East end boys and west end girls:/s/-fronting in Southeast England. University of Pennsylvania Working Papers in Linguistics, 19(2):111-120.

Llamas, Carmen (2007). "A place between places": Language and identities in a border town. Language in Society 36(4):579-604

McCloy, Daniel (2016). phonR: tools for phoneticians and phonologists. R package version 1.0-7.

Milroy, Lesley (1987). Language and Social Networks. Blackwell: Oxford Montgomery, Chris, \& Moore, Emma (2017) Language and a sense of place: Studies in language and region. Cambridge: Cambridge University Press.

Moore, Emma (2010) The Interaction between Social Category and Social Practice:

Explaining was/were variation. Language, Variation \& Change 22(3): 347-371

Moore, Emma, \& Montgomery, Chris (2017). Introduction. In C. Montgomery \& E. Moore (Eds.), Language and a sense of place: Studies in language and region (pp. 1-12). Cambridge: Cambridge University Press. doi:10.1017/9781316162477.002

Nijmegen: Max Planck Institute for Psycholinguistics (2019). ELAN (Version 5.4) [Computer software]. 
Office for National Statistics (2016): 2011 Census aggregate data. UK Data Service (Edition: June 2016).

Orton, Harold (1962). Introduction to the Survey of English Dialects. E.J. Arnold, Leeds.

Powell, W. R. (1956). Loughton: Introduction. In A History of the County of Essex: Volume 4, Ongar Hundred. 110-114. British History Online http://www.britishhistory.ac.uk/vch/essex/vol4/pp110114 [accessed 11 August 2017].

Rosenfelder, Ingrid; Fruehwald, Josef; Evanini, Keelan; Seyfarth, Scott; Gorman, Kyle;

Prichard, Hilary; Yuan, Jiahong (2014). FAVE (Forced Alignment and Vowel Extraction)

Program Suite v1.2.2 10.5281/zenodo.22281

Shaw, Jason; Best, Catherine; Docherty, Gerard; Evans, Bronwen; Foulkes, Paul; Hay, Jennifer; \& Mulak, Karen (2018). Resilience of English vowel perception across regional accent variation. Laboratory Phonology. 1868-6354

Silverstein, Michael (2003). Indexical order and the dialectics of sociolinguistic life. Language \& communication. 23(3-4):193-229.

Sivertsen, Eva (1960). Cockney Phonology. Oslo, Oslo University Press.

Torgersen, Eivind, \& Kerswill, Paul (2004). Internal and External Motivation in Phonetic Change: Dialect Levelling Outcomes for an English Vowel shift'. Journal of Sociolinguistics. 8: 23-53.

Trudgill, Peter (2008). The dialect of East Anglia: phonology. In Bernd Kortmann \& Clive Upton (eds.), Varieties of English, 178-193. Mouton de Gruyter. 
Vertovec, Steven (2007). Super-diversity and its implications. Ethnic and Racial Studies 30(6):1024-1054

Watt, Paul; Millington, Gareth; \& Huq, Rupa (2014). East London Mobilities: The 'Cockney Diaspora' and the remaking of the Essex ethnoscape. In Watt, P. \& Smets, P. (Eds.) Mobilities and neighbourhood belonging in cities and suburbs, pp. 121-144. Palgrave Macmillan UK. Wells, John (1982). Accents of English 2: The British Isles. Cambridge: Cambridge University Press.

Wells, John (1994). The Cockneyfication of RP? In Gunnel Melchers \& Nils-Lennart Johannesson (eds.), Nonstandard varieties of language, 198-205. Stockholm: Almqvist \& Wiksell

Williams, Ann, \& Kerswill, Paul (1999). Dialect levelling: Change and continuity in Milton Keynes, Reading and Hull. In P. Foulkes \& G. Docherty (eds.), Urban voices. Accent studies in the British Isles, 141-162. London: Arnold.

Young, Michael, \& Willmott, Peter (1957). Family and Kinship in East London. London: Routledge and Kegan Paul 


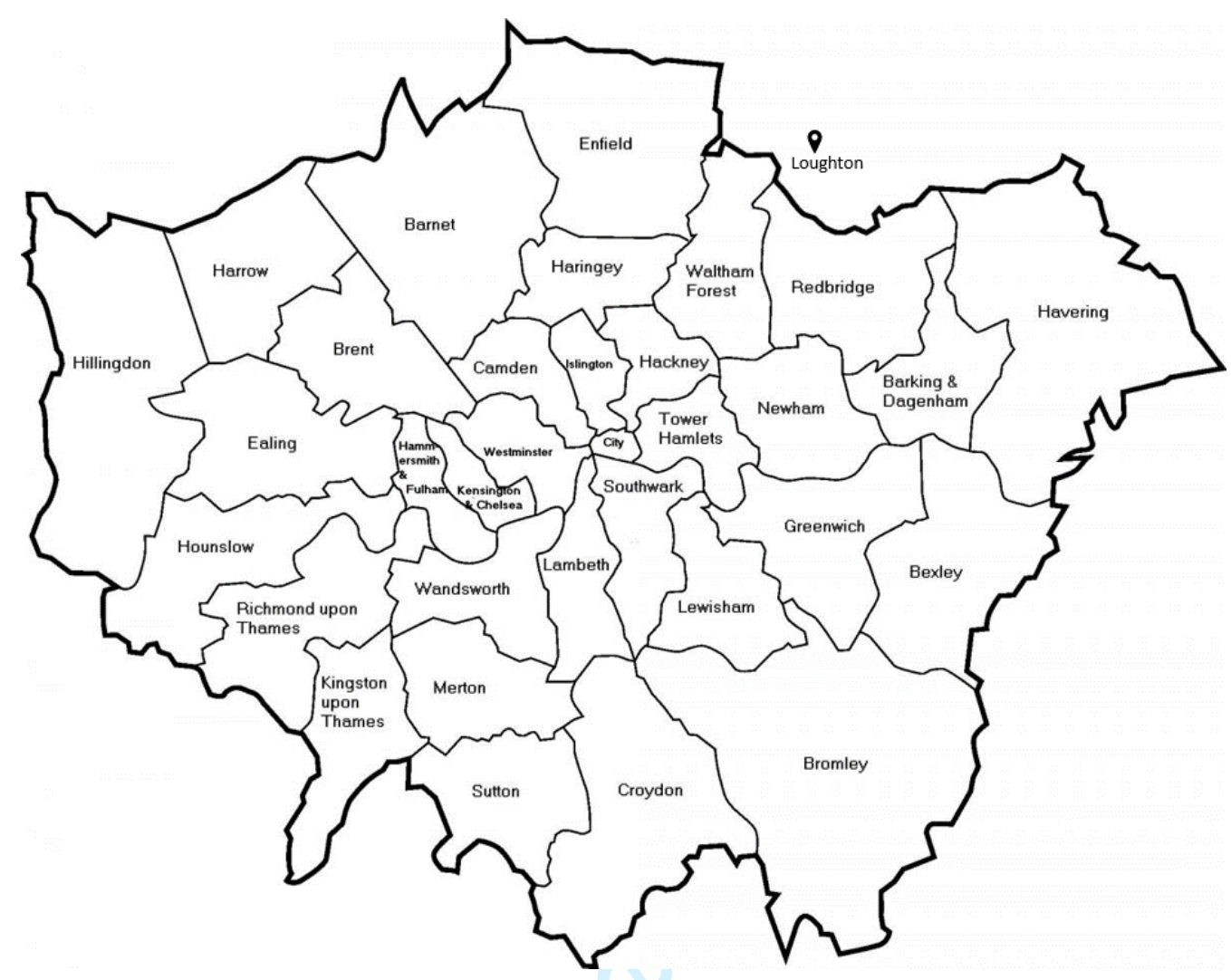

Figure 1. Map of Greater London showing the London boroughs and the position of Loughton, where Debden is situated. Whilst Loughton is officially under the jurisdiction of Essex it is 5 miles from the Greater London border, and is as geographically as close to central London as some outer-London boroughs such as Havering. 


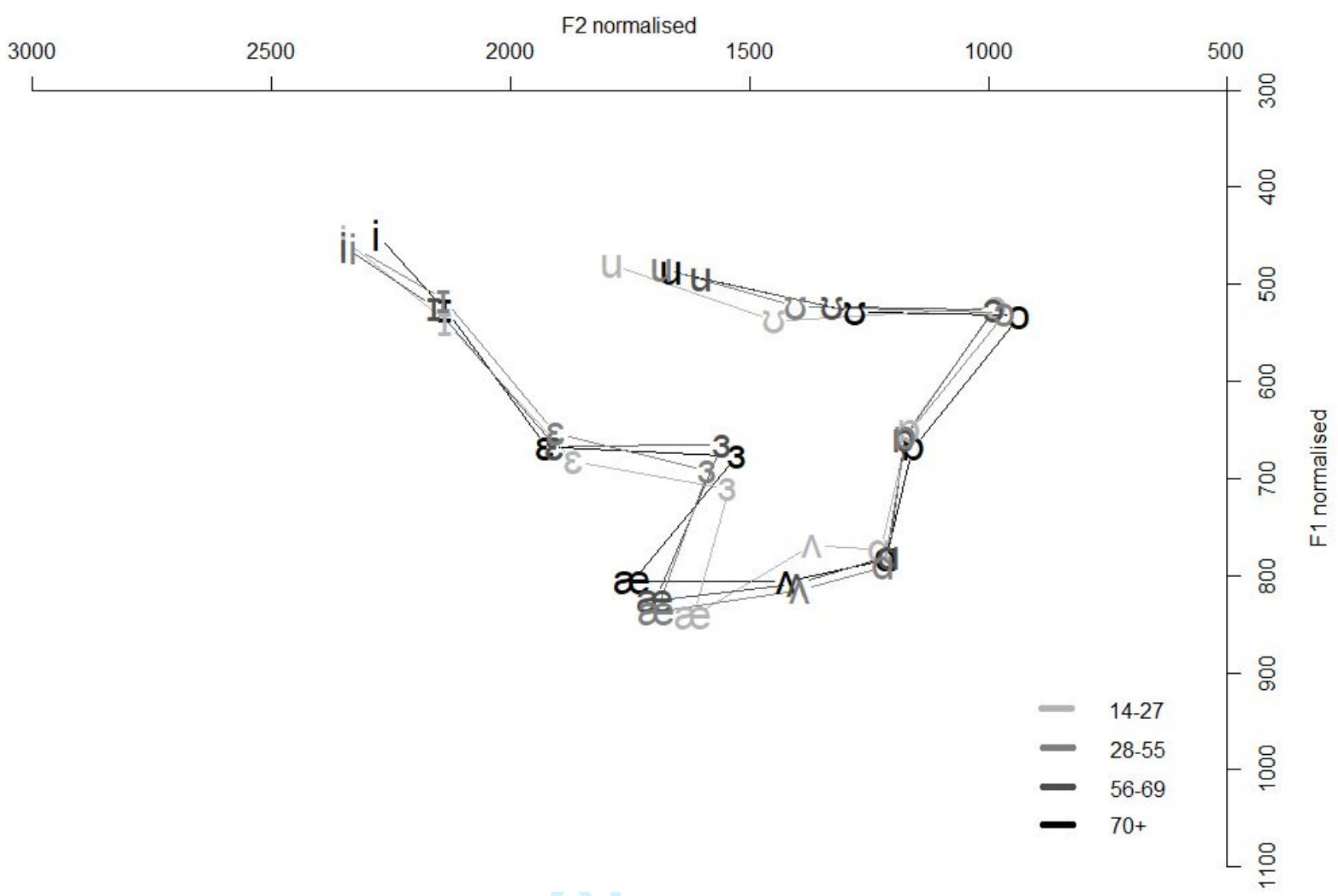

Figure 2. F1-F2 formant frequency plots of participants' productions of monophthongs, averaged across age groups. There is some evidence of change away from traditional Cockney vowels, e.g. the backing of TRAP, and the raising of the STRUT vowel. 


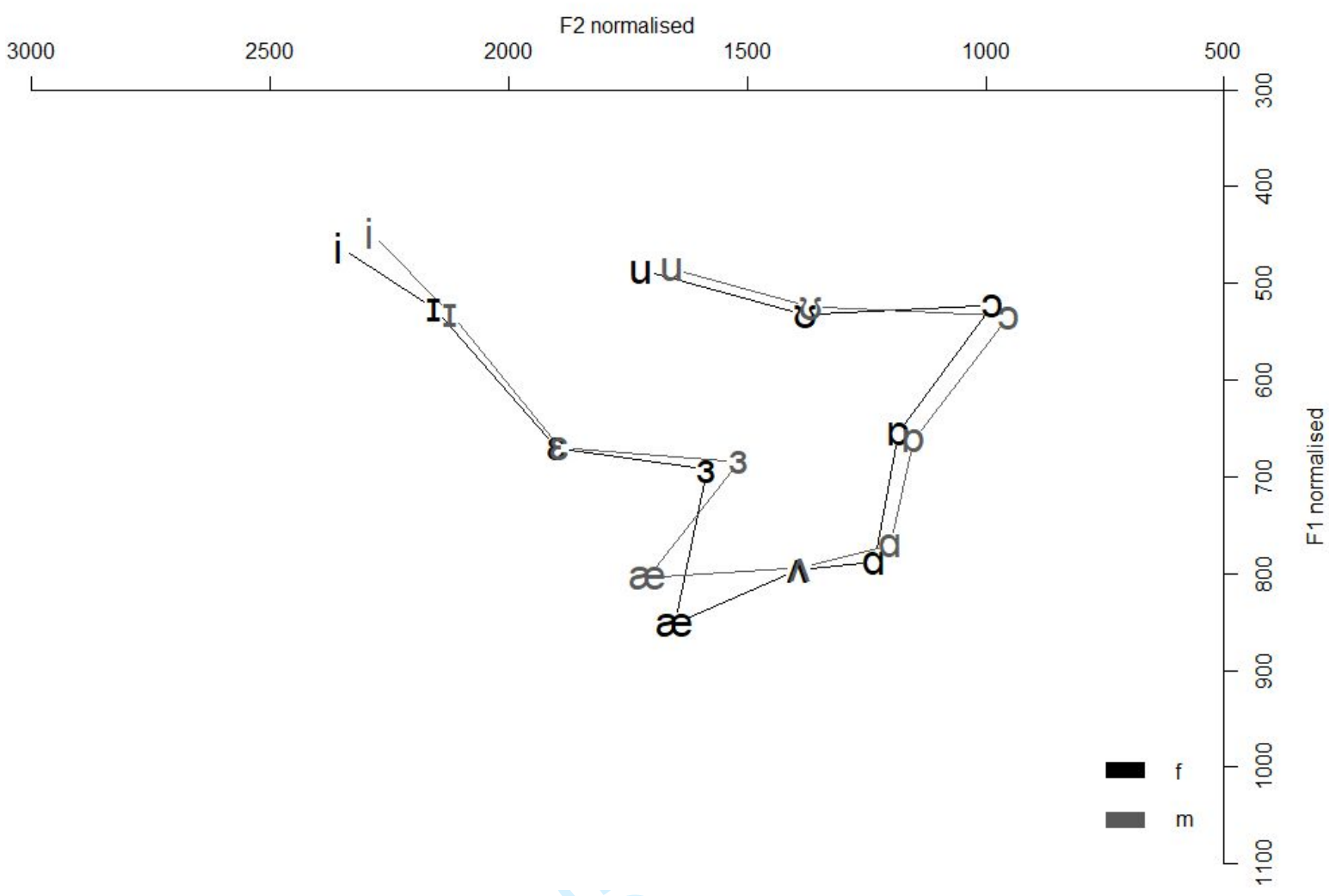

Figure 3. F1-F2 formant frequency plots of participants' productions of monophthongs, averaged by gender $(f=$ female, $m=$ male). The most notable difference is the lowered and backed TRAP vowel in women, though this is raised in both male and female speakers. 


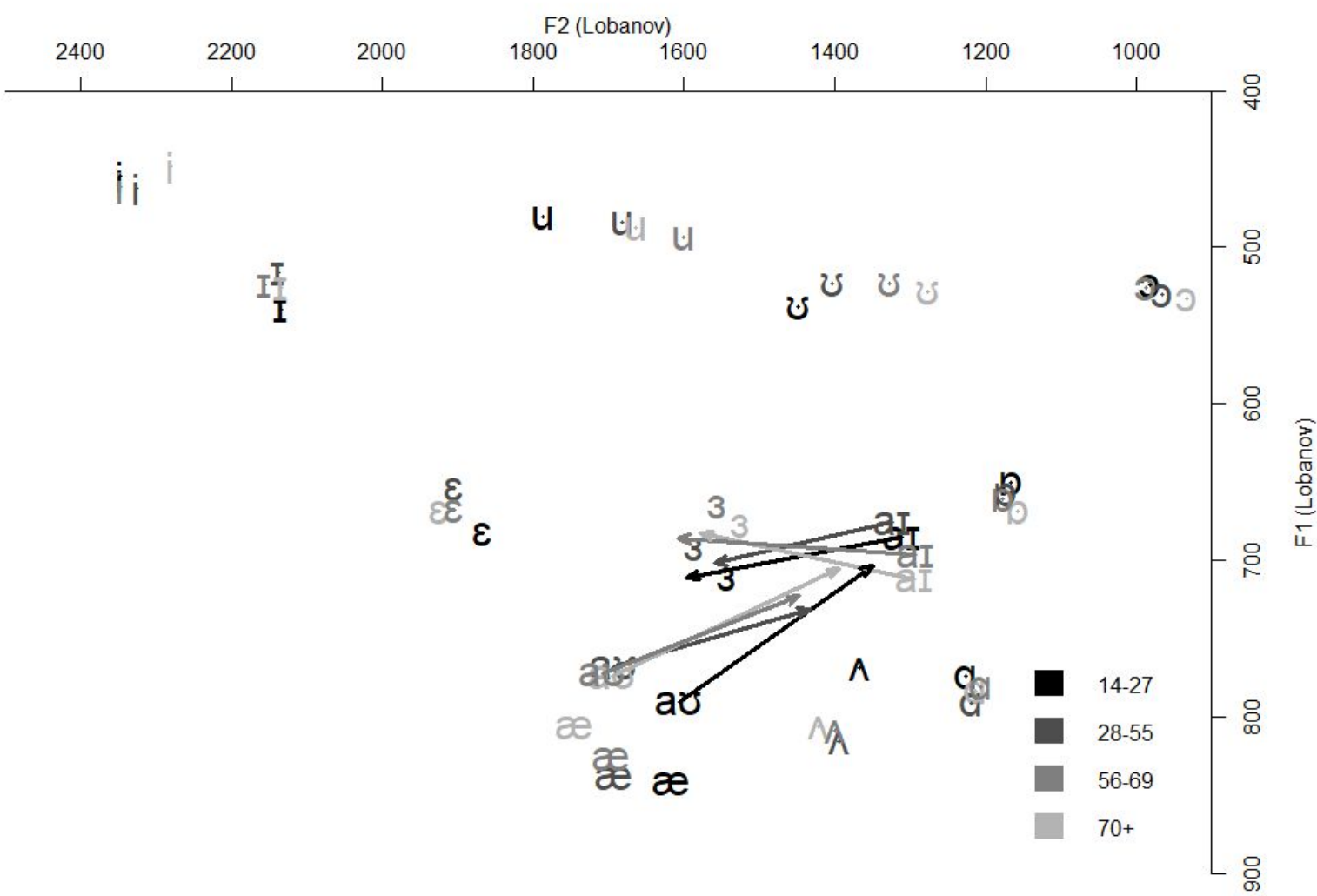

Figure 4. F1-F2 formant frequency plots showing trajectories of participants' productions of the PRICE and MOUTH vowels, measured at $20 \%$ and $80 \%$ of the vowel duration and averaged across age groups.The 14-27 age group have fronted onsets for the MOUTH vowel compared to all other groups. 


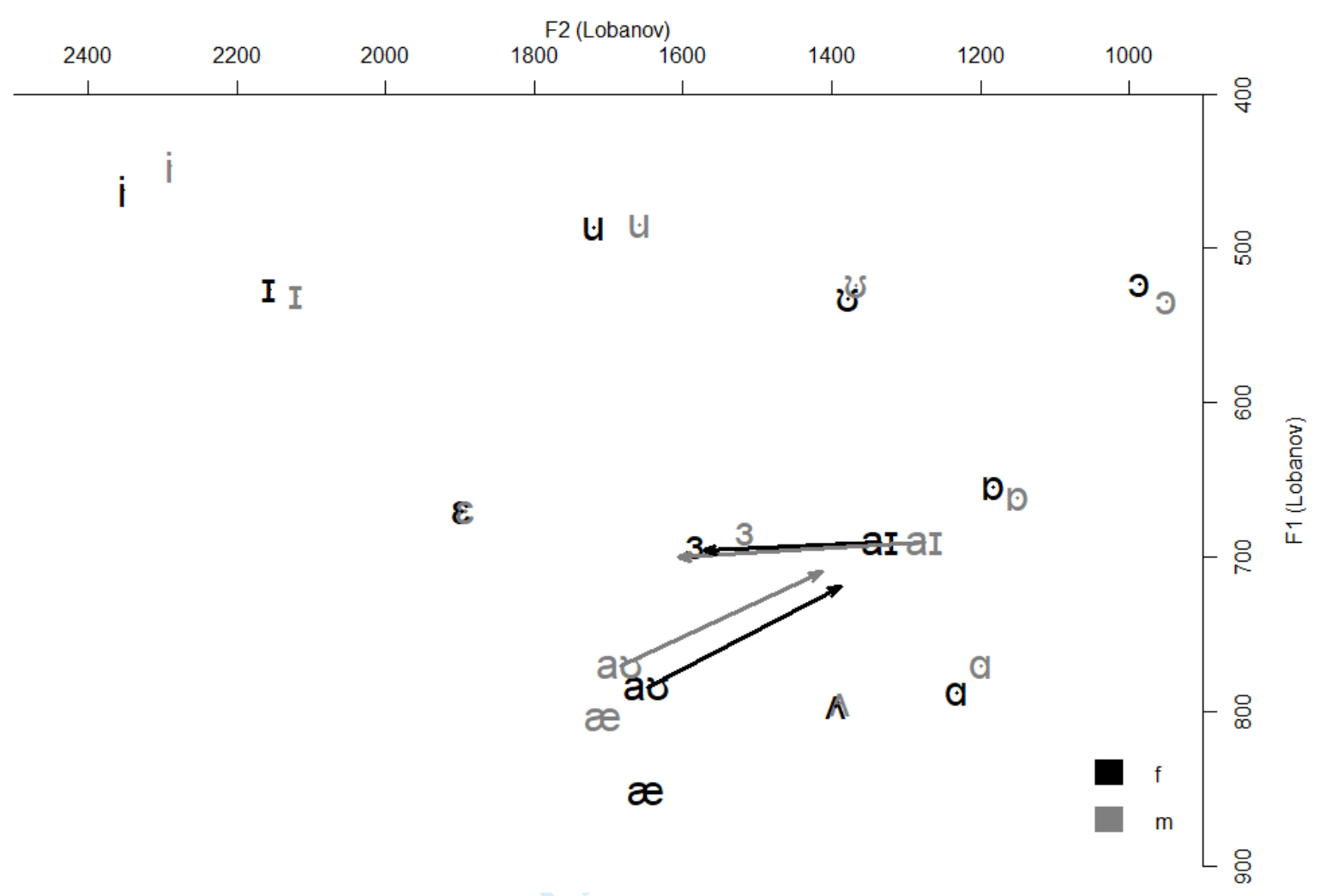

Figure 5. F1-F2 formant frequency plots showing trajectories of participants' productions of the PRICE and MOUTH vowels, measured at $20 \%$ and $80 \%$ of the vowel duration and averaged across gender ( $\mathrm{f}=$ female, $m=$ male). There were no significant gender differences for either of these vowels. 
Cockney identity

sex 白白 m

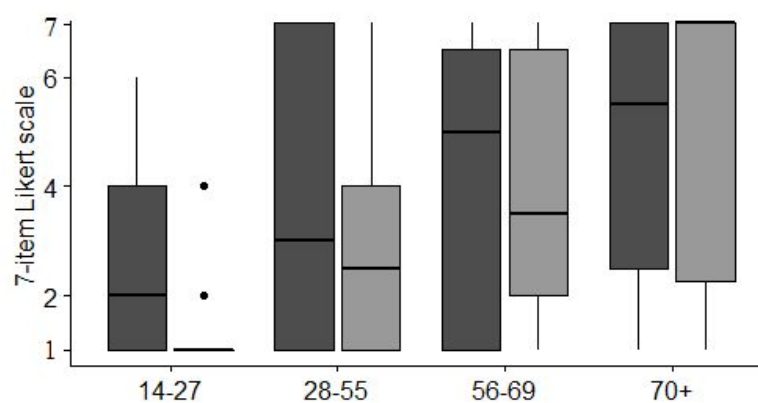

Essex accent sex市审 m
East London accent

sex自白 $\mathrm{m}$

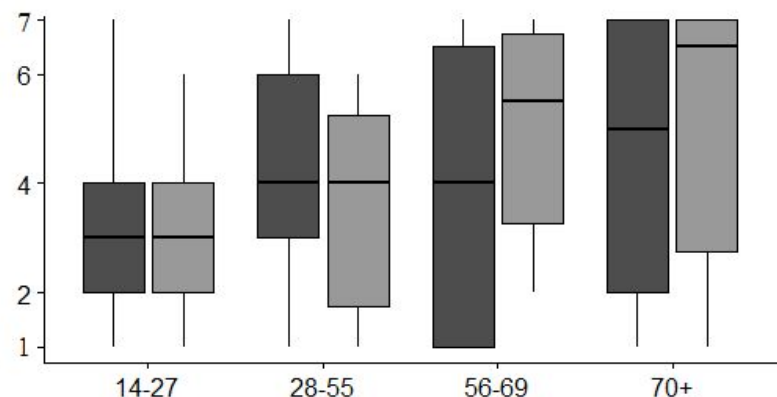

sex 甶自
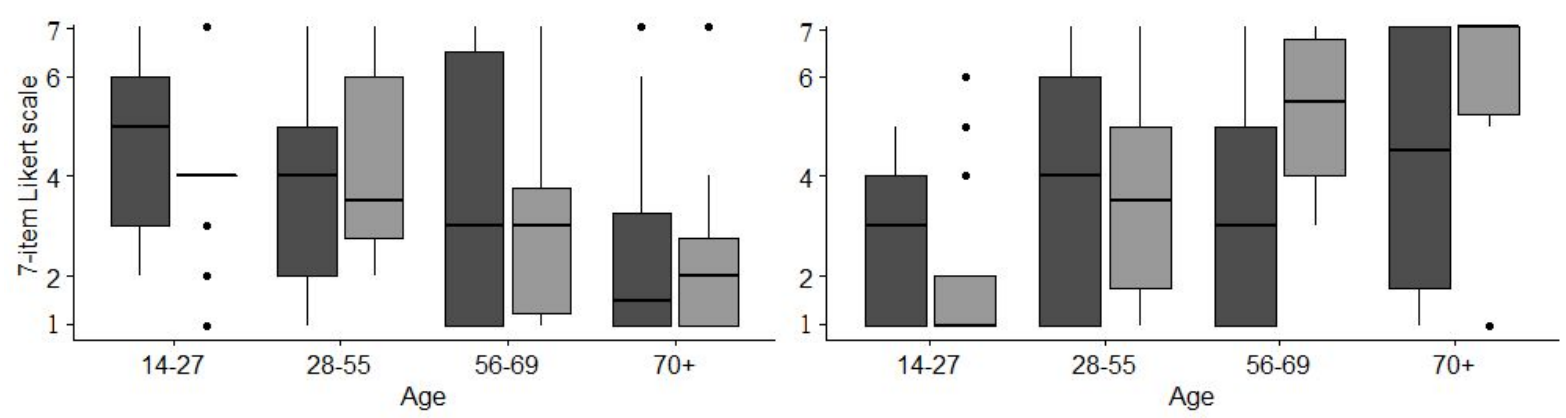

Figure 6. Boxplots showing questionnaire responses for whether participants 1) considered

themselves to be Cockney (top left); 2) believed they spoke with an Essex accent (bottom left); 3)

believed they spoke with an East London accent (top right); or 4) believed they spoke with a Cockney accent (bottom right). There has been a reduction in apparent-time of identifying with a Cockney or East London accent as well as a Cockney identity. This has been led by men. Young speakers are more likely than older speakers to identify their accent as Essex. 